\title{
Design, management and control of demanufacturing and remanufacturing systems
}

\author{
Tullio Tolio (1) ${ }^{\mathrm{a}, \mathrm{b}, *}$, Alain Bernard (1) ${ }^{\mathrm{c}}$, Marcello Colledani $(2)^{\mathrm{a}, \mathrm{b}}$, Sami Kara $(1)^{\mathrm{d}}$, \\ Guenther Seliger $(1)^{\mathrm{e}}$, Joost Duflou $(1)^{\mathrm{f}}$, Olga Battaia ${ }^{\mathrm{g}}$, Shozo Takata $(1)^{\mathrm{h}}$ \\ a Politecnico di Milano, Department of Mechanical Engineering, Via la Masa, 1, 20156 Milan, Italy \\ ${ }^{\mathrm{b}}$ ITIA-CNR, Institute of Industrial Technologies and Automation, Via Bassini 15, 20133 Milan, Italy \\ ${ }^{\mathrm{c}}$ Ecole Centrale de Nantes, 1, rue de la Noë, 92101 Nantes, France \\ ${ }^{\mathrm{d}}$ The University of New South Wales, School of Mechanical and Manufacturing Engineering, 2052 Sydney, Australia \\ e TU Berlin - Institute for Machine Tools and Factory Management, Pascalstr. 8-9, 10587 Berlin, Germany \\ ${ }^{\mathrm{f}}$ KU Leuven, Celestijnenlaan, 300, 24223001 Heverlee, Leuven, Belgium \\ ${ }^{\mathrm{g}}$ Institut Supérieur de l'Aéronautique et de l'Espace, ISAE-Supaéro, Toulouse, France \\ ${ }^{\mathrm{h}}$ School of Creative Science and Engineering, Waseda University, Tokyo, Japan
}

\section{A R T I C L E I N F O}

\section{Keywords:}

Sustainable development

System

Circular Economy

\begin{abstract}
A B S T R A C T
In the recent years, increasing attention has been posed towards enhancing the sustainability of manufacturing processes by reducing the consumption of resources and key materials, the energy consumption and the environmental footprint, while also increasing companies' competitiveness in global market contexts. De- and remanufacturing includes the set of technologies/systems, tools and knowledge-based methods to recover and reuse functions and materials from industrial waste and postconsumer products, under a Circular Economy perspective. This new paradigm can potentially support the sustainability challenges in strategic manufacturing sectors, such as aeronautics, automotive, electronics, consumer goods, and mechatronics. A new generation of smart de- and remanufacturing systems showing higher levels of automation, flexibility and adaptability to changing material mixtures and values is emerging and there is a need for systematizing the existing approaches to support their operations. Such innovative de- and remanufacturing system design, management and control approaches as well as advanced technological enablers have a key role to support the Circular Economy paradigm. This paper revises system level problems, methods and tools to support this paradigm and highlights the main challenges and opportunities towards a new generation of advanced de- and remanufacturing systems.
\end{abstract}

(C) 2017 Published by Elsevier Ltd on behalf of CIRP.

\section{Introduction, motivation and objectives}

\subsection{Context, opportunities and benefits of Circular Economy}

Circular Economy has been recently proposed as a new paradigm for sustainable development, showing potentials to generate new business opportunities in worldwide economies and to significantly increase resource efficiency in manufacturing [175].

The vision of the Circular Economy paradigm is to fundamentally change the current linear "take-make-dispose" economic approach, which is cause of massive waste flows. For example, in the fast-growing consumer goods sector alone, about $80 \%$ of the $\$ 3.2$ trillion material value is lost irrecoverably each year worldwide [304]. In contrast, Circular Economy is an industrial

\footnotetext{
* Corresponding author at: Politecnico di Milano, Department of Mechanical Engineering, Via la Masa, 1, 20156 Milan, Italy and ITIA-CNR, Institute of Industrial Technologies and Automation, Via Bassini 15, 20133, Milan, Italy.

E-mail address: tullio.tolio@polimi.it (T. Tolio).
}

system that is restorative and regenerative by intention and design [175]. It aims to keep products, components, and materials at their highest utility and value along their life-cycle. It replaces the product 'end-of-life' concept with restoration and aims for the elimination of waste through the superior design of materials, products, systems, and, within this, business models.

Recent studies show that a transition to Circular Economy may represent a new sustainable growth path as well as a business opportunity for the worldwide manufacturing industry [82]. In a world of close to 9 billion people expected by 2030 - including 3 billion new middle-class consumers - the challenges of expanding resource supply to meet future demand are unprecedented. Without a rethinking of how society uses materials in the linear economy, elements such as gold, silver, indium, iridium, tungsten and many others vital for industry could be depleted within the next 5-50 years [304]. A new industrial model that decouples revenues from material input, and production from resource consumption is needed for achieving a sustainable development path, both in early-industrialised countries and in emerging economies [243]. A sustainable transition to Circular Economy is expected to bring benefits in environmental, economic 
and social terms. In environmental terms, Circular Economy practices have potential to bring $80 \%-90 \%$ savings in raw materials and energy consumption with respect to the production of the same goods in the traditional linear model, strongly contributing to $\mathrm{CO}_{2}$ emissions reductions and positively affecting the climate change. In economic terms, the major benefits of Circular Economy for manufacturers are brought by the reduction of material and energy costs coupled with the reduction of end-of-life materials disposal costs. This, in turn, translates into a general product price reduction of around $25 \%-30 \%$, that can boost the availability of high quality affordable products, thus increasing companies' competitiveness in emerging markets. A recent study showed that by shifting toward a Circular Economy model the European economy could achieve annual benefits of $€ 0.9$ trillion by 2030, in addition to the $€ 0.9$ trillion that could potentially be brought by the ongoing European digital transformation of businesses [177]. In social terms, Circular Economy businesses are expected to bring new jobs by boosting an increased consumption of sustainable products driven by the lower prices.

Due to these features, Circular Economy is achieving increasing importance in the worldwide political and research agendas. The G7 Summit Declaration of June 2015 has launched the "Alliance on Resource Efficiency" to promote Circular Economy, Remanufacturing and Recycling as strategic actions for limiting the consumption of natural resources and reducing waste. At European level, the Commission launched in December 2015 the strategic initiative "Closing the loop - An EU action plan for the Circular Economy" [69]. In China, Circular Economy is seen as a new model for industrialisation and an integrated strategy to essentially reform the traditional patterns of economic growth and social development for contrasting the effects of the massive urbanisation and the environmental problems. Since 2006, Circular Economy initiatives are promoted in the Chinese "Five Year Plan" of development [305,253]. Similar initiatives have been initiated in US, Japan, and Australia.

However, a sustainable transition to Circular Economy businesses will need to be supported by fundamental innovations, driven by the manufacturing industry, at systemic level, encompassing product design, value-chain integration, business models, ultimately posing new challenges on the way demanufacturing and remanufacturing technologies and systems are conceived and implemented. Demanufacturing and remanufacturing, briefly indicated as de- and remanufacturing, are fundamental technical solutions for an efficient and systematic implementation of Circular Economy. More formally, De- and remanufacturing includes the set of technologies and systems, tools and knowledge-based methods to systematically recover, reuse, and upgrade functions and materials from industrial waste and post-consumer products, to support a sustainable implementation of manufacturer-centric Circular Economy businesses. While demanufacturing liberates target materials and components, remanufacturing restores or upgrades their functions.

This paper provides an overview and a framework of the industrial practices, scientific methodologies, and enabling technologies to profitably design, manage and control de- and remanufacturing systems. It also identifies key open research and practical issues that need to be addressed by the research community. The key questions that this paper addresses can be formulated as follows: "What are the main industrial barriers for a profitable implementation of Circular Economy businesses by manufacturers?" and "Which tools can support the development of the next-generation de- and remanufacturing systems?".

The paper is structured as follows. The next paragraphs present the key definitions and concepts concerning different options for implementing circular businesses and introduce a set of real cases that provide the industrial motivation to the problem. Section 2 proposes a new framework that highlights the role of the manufacturing industry in the implementation of Circular Economy solutions. Sections 3-5 revise, respectively, the state-of-the art methods and tools and the enabling technologies supporting the design, management and control of efficient de- and remanufacturing systems. Section 6 discusses socio-economic boundaries to
Circular Economy. Finally, Section 7 describes promising future research topics in this area.

\subsection{Definitions and key concepts}

The Circular Economy concept cannot be traced back to one single date or author, but it finds its root in several schools of thought. The theory of "Regenerative Design" by Lyle introduced in the late 70 s the idea of linking sustainable development to the concept of resource regeneration [174]. The economic basis for a transition to a non-linear industrial model was originally introduced by Stahel in Ref. [251] and further refined with the idea of "Cradle-to-Cradle" design [187]. It is an economic, industrial and social framework that seeks to create systems that are not only efficient but also essentially waste free. This model was applied to industrial design and manufacturing, social systems and urban environments. "Industrial Ecology" [75], i.e. the study of material and energy flows through industrial systems, also has links to the Circular Economy concept. Focusing on connections between operators within the 'industrial ecosystem', this approach aims at creating closed-loop processes in which waste serves as an input. As Circular Economy, also Industrial Ecology adopts a systemic point of view, designing production processes in accordance with local ecological constraints, while looking at their global impact from the outset. More recently, the "Blue Economy" movement originated by Pauli, collected practical cases where the resources are connected in cascading systems and the waste of one product becomes the input to create a new cash flow [209]. The modern concept of Circular Economy can be attributed to the MacArthur Foundation [176]. Four different mechanisms for value creation in Circular Economy were introduced that offer opportunities in comparison with linear usage. They are referred to as:

- The power of inner circle: the closer the product gets to direct reuse, i.e., the perpetuation of its original purpose, the larger the cost savings will be in terms of material, labour, energy, capital and the associated externalities.

- The value of circling longer: value created by keeping products, components, and materials in use longer within the Circular Economy. This can be achieved by enabling more cycles or by spending more time within a single cycle.

- The power of cascaded use: value created by using discarded materials from one value chain as by-products, replacing virgin material in another.

- The power of pure circles: uncontaminated material streams increase collection and redistribution efficiency while maintaining quality.

At technical levels, different business options for Circular Economy have been proposed to generate benefits by exploiting these value-creation mechanisms. For example, Jawahir in its definition of "Sustainable Manufacturing" proposes the so-called 6Rs model, where the traditional 3R model based on the Reduce, Reuse, Recycle practices is enriched with three additional actions namely Recover, Redesign, and Remanufacture [121,120]. In practice, the following Circular Economy options and the related business models are implemented in the industrial practice:

Reuse: a generic term covering all operations where a return product is put back into service, essentially in the same form, with or without repair or remediation [206].

Repair: the correction of specified faults in a product [206]. Repair refers to actions performed in order to return a product or component purely to a functioning condition after a failure has been detected, either in service or after discard [207].

Remanufacturing for function restore: it returns a used product to at least its original performance with a warranty that is equivalent or better than that of the newly manufactured product. A remanufactured product fulfils a function similar to the original part. It is remanufactured using a standardised industrial process, in line with technical specifications [11]. 
Remanufacturing for function upgrade: the process of providing new functionalities to products through remanufacturing. Remanufacturing with upgrade aims to extend products' value life enabling the introduction of technological innovation into remanufactured products in order to satisfy evolving customers' preferences and, at the same time, preserving as much as possible the physical resources employed in the process [39].

Closed-loop recycling: recycling of a material can be done indefinitely, without properties degradation (upcycling). In closedloop recycling, the inherent properties of the recycled material are not considerably different from those of the virgin material, thus substitution is possible [108].

Open-loop recycling: the conversion of material from one or more products into a new product, involving degradation in the inherent material properties (downcycling). In open-loop recycling, the inherent properties of the recycled material differ from those of the virgin material in a way that it is only usable for other product applications, substituting other materials [108].

These options entail different value and material preservation levels. While reuse, repair and remanufacturing constitute product functions and materials conservation scenarios, recycling offers a material recovery scenario. Their implementation calls for different de- and remanufacturing systems capabilities, which will be discussed by practical industrial cases in the next paragraph and further generalised in Section 2.

\subsection{Industrial motivation}

In order to highlight the main practical implications related to the implementation of Circular Economy options in different industrial sectors, a comprehensive set of real industrial cases have been collected. These case studies have been gathered by analysing existing publications, running industrial projects, both publicly and privately funded, and by authors' expertise. They include various production sectors, such as the automotive, railway, electronics, aerospace, heavy machinery and industrial machine industries. Moreover, they include the most valuable spectra of Circular Economy options and related systems such as reuse, remanufacturing for regeneration and upgrade, and recycling for material upcycling. In line with the objective of the paper, the common feature of these real cases is the strong involvement of the manufacturer in the de- and remanufacturing operations. The focus is on implementations of Circular Economy solutions in which the product manufacturer plays a key role in the business. Therefore, more traditional examples of recycling for material downcycling are not addressed.

Komatsu Ltd. is the second largest manufacturer of construction and mining equipment in the world. The customers demand durable and comfortable machines, which can operate without catastrophic failures for more than 10 years under harsh conditions. To respond to such customer demands, OEMs need to take total responsibility of maintenance, repair, and overhaul (MRO) tasks. To meet these challenges, since the early 2000s, Komatsu introduced a remote monitoring system called KOMTRAX, shown in Fig. 1, which nowadays is considered as an IoT or

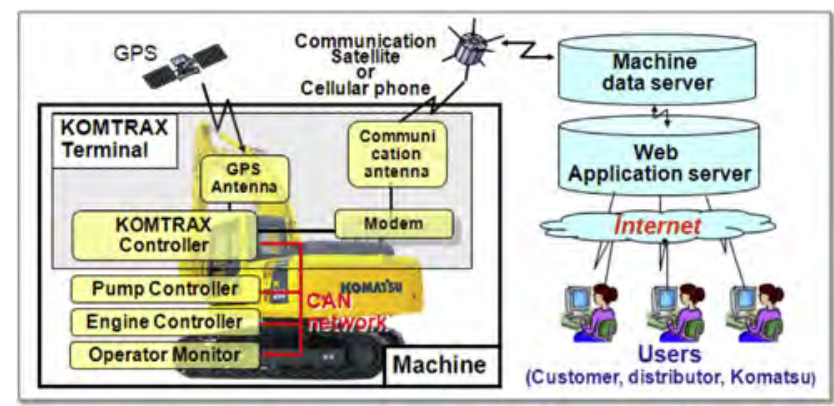

Fig. 1. KOMTRAX system.
M2 M system. Through sensors and on-board computers, KOMTRAX monitors not only the physical conditions of components, such as engines, hydraulic components, and suspensions, but also their operating conditions. The monitored data are utilised for planning MRO and remanufacturing to reduce the maintenance cost and risk of unexpected breakdown. For example, the wear of a piston ring and cylinder liner can be estimated by monitoring the pressure of blow-by gas, and an alarm is issued when it exceeds a fixed threshold. The operational data are also used for advising the customers on specific opportunities for improvement, contributing to the reduction of the operation cost, which accounts for a substantial fraction of the life cycle cost of this equipment. In addition, Komatsu has introduced a component traceability system to support on-site component exchange performed by the customers.

The accumulated data acquired by KOMTRAX, as well as the knowledge extracted from data, have become an asset and a competitive edge for Komatsu in its life-cycle support of equipment. The data are also fed back for developing the next generation equipment. However, identifying failure symptoms is not always an easy task, especially when the failure mechanism is unknown. Although machine learning and AI technologies are promising for this purpose, it is still necessary for the company to develop the technology to apply them in actual cases, where the operation environment varies significantly and the available failure data are limited.

Ricoh Company Ltd. is one of the pioneer companies in introducing environmental management. Since the early 90s, Ricoh has developed reuse and recycling technologies based on the "Concept of a Sustainable Society: The Comet Circle ${ }^{\mathrm{TM}}$ " [105] and implemented these technologies in its Office Automation (OA) business. The company is conducting circular manufacturing by: (a) remanufacturing reconditioned (RC) copiers, (b) reusing parts as spare parts, and (c) closed-loop recycling. It is also making efforts to improve product design for an easier application of 3R technologies. The Ricoh Eco Business Development Center, opened in 2016, has integrated its reuse and recycling facilities for OA devices that are distributed in 12 locations across Japan. In this center, the company conducts feasibility studies on the environmental technologies with the aim of creating new eco businesses and executing reuse and recycling activities (Fig. 2).

Ricoh's management policy is to reduce resource consumption and environmental load, and to increase profit in parallel. In fact, the company turned its reuse and recycling business profitable in 2006, as a result of its efforts in establishing circular manufacturing since the 90s. Its competitive edge in the circular manufacturing business lies in the high rate of product return, efficient recovery technologies, and improved Return on Investment (ROI), owing to the expansion of its business scale. Those advantages are supported by various technologies, such as prediction of the amount of collected products, recovery cost estimation based on diagnosis of collected products, and dry media cleaning using plastic films and shells of crabs.

Through circular manufacturing, the company enjoys a competitive advantage even in the second-hand machine market

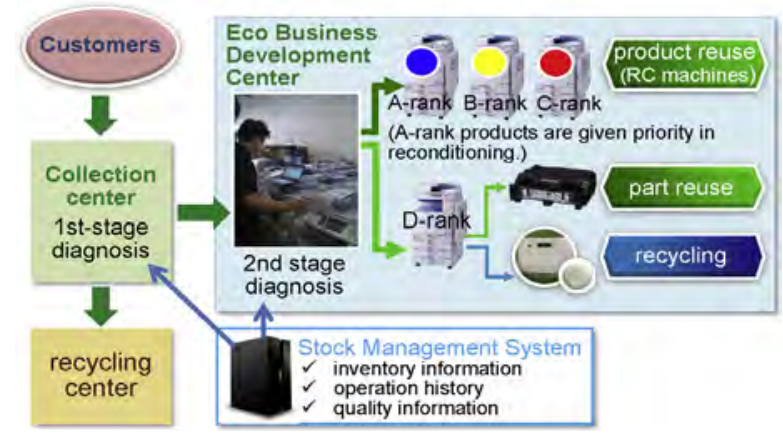

Fig. 2. Ricoh's reuse and recycling system. 
by providing $\mathrm{RC}$ machines. It is also reducing maintenance cost by means of spare parts reuse. The price competitiveness of $\mathrm{RC}$ machines and reuse parts is effective for winning a major contract. The company announced its Long-Term Environmental Vision, in which it plans to reduce new resource inputs, from the 2007 level, by $25 \%$ up to 2020 and by $87.5 \%$ until 2050 [106]. To achieve these goals, Ricoh is developing various challenging technologies in its Eco Business Development Center, such as plastic-to-oil conversion, forest biomass utilisation, and optimisation of reverse logistics.

Knorr Bremse is a leading global provider of braking systems for rail and commercial vehicles and a major player in remanufacturing activities. Remanufacturing is an established business for the company. A total number of 300 individual product types are currently remanufactured. As part of the company's aftermarket service, a wide range of remanufactured products such as electronic air controls, compressors and electronic pneumatic modules are offered to customers.

The automotive industry has a long history of reuse and recycling. In addition to the economic advantages, remanufacturing contributes to compliance with the existing legislation, steadily lifting the target level of reuse and recycling up to 95\% in 2015. Market forecasts indicate that the commercial vehicle population is continuously ageing and the customers have become more price-sensitive than ever as a result of the crisis. These trends have recently boosted remanufacturing businesses. According to APRA - Automotive Part Remanufacturer Association, the number of parts currently remanufactured in Europe is 35 million units per year. This quantity is expected to grow to 39 million units per year by 2020 . Moreover, in the aftermarket, which represents roughly the $45 \%$ of the total automotive industry turnover, the customer preference goes to remanufactured parts in the $75 \%$ of the cases. As a consequence, the company is investing in increasing the production capacities and sell premium quality remanufactured products.

According to an in-depth study carried out by Knorr Bremse [150], remanufacturing of Electronic Braking System (EBSs) provides benefits in terms of material and energy consumption. A remanufactured part consumes only the $10 \%$ of aluminium and requires the $10 \%$ of the energy to be processed, with respect to the same new part. The financial savings for the customer is between the $10 \%$ and the $20 \%$ with respect to new parts.

The current remanufacturing process is carried out in a plant of $9.000 \mathrm{~m}^{2}$ in Czech Republic and the regenerated components are reassembled in the main assembly line, Fig. 3, also used for new components, in Germany, in order to ensure the same quality as for newly-manufactured original parts. In the current process-chain, the collected post-use product, called "core" in the remanufacturing business, is manually inspected, remanufacturing decisions are taken by the operator and, if the product is considered to be adequate for remanufacturing, a manual disassembly process is applied on the basis of Standard Operation Sheets. The Printed Circuit Boards (PCBs) are manually remanufactured, and cleaning and refurbishing operations are carried out with a semi-automated processes.

Core collection and information management is a critical aspect for the implementation of the remanufacturing process-chain. Cores are usually gathered from three different sources, namely internal service centres, independent service centres, or core dealers. A major success factor for the Knorr-Bremse remanufacturing business is the capability of owning and properly exploiting a deep knowledge about the product materials and critical functional requirements, being Knorr-Bremse also the manufac-

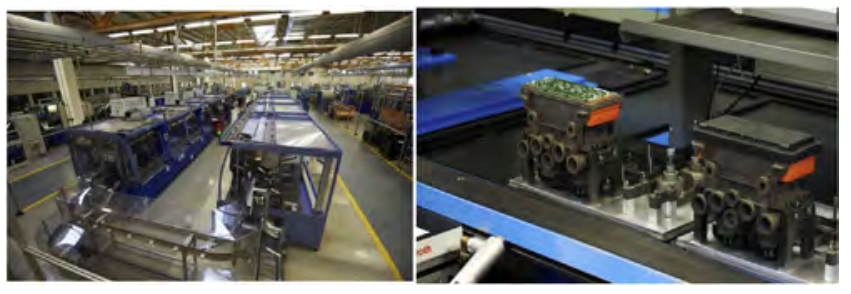

Fig. 3. View of the reassembly line at Knorr-Bremse [149]. turer of these components. This fundamental asset enables the company to exploit the synergies between the manufacturing and remanufacturing processes and systems, maximizing the addedvalue throughout the product life-cycle. However, the remanufacturing phase is characterised by large variability in the condition of the input post-use products, not observed during the manufacturing phase. This feature calls for human-intensive operations in remanufacturing. This motivates the choice of performing remanufacturing operations in low-wage countries, although an increase in logistics cost for transferring the regenerated parts from the remanufacturing to the reassembly plant is encountered. In order to smooth the effect of the variability in the condition of input post-consumer products in remanufacturing, innovation areas have been developed within the European Project "RobustPlaNet" [66]. These include the development of inline inspection technologies, decision support systems and disassembly planning tools to adapt the remanufacturing process to the specific conditions of the parts under processing. Moreover, specific solutions for PCB diagnostics, failure mode analysis and automatic electronics remanufacturing have been investigated. These innovations may contribute to improve product regeneration rates and decrease remanufacturing costs, thus boosting the competitiveness of industry in this sector.

As leading supplier of motor vehicle spare parts, Bosch developed the "Bosch eXchange program" to reduce the volume of raw materials they use, and, where possible, feed materials back into the production cycle. This remanufacturing program involves different product groups (i.e. starters and alternators, diesel systems and control units) that are subject to a standardised remanufacturing process (Fig. 4). The product is disassembled, cleaned, components are repaired or replaced, and the individual components as well as the whole product are tested to ensure that the original design specifications are met. Besides the availability of the core to be processed, a fundamental success factor is related to the ability to control the return flow in the manufacturer production/recycling process. In this perspective, information technology and reverse-logistics could potentially be the enablers for the implementation of this sustainable business. Bosch carries out its European Remanufacturing activities in its plants in Germany, Ukraine (Fig. 5) and Slovakia.

A key challenge is the human intensive tasks in remanufacturing and the intensive competition based on labour costs, especially for products such as starters and generators with a well-developed independent remanufacturing industry. As a result Bosch performs a two-sided strategy: increasing automation in the German plant, while transferring labour intensive tasks to the plants in Ukraine and Slovakia. Automated remanufacturing processes are already

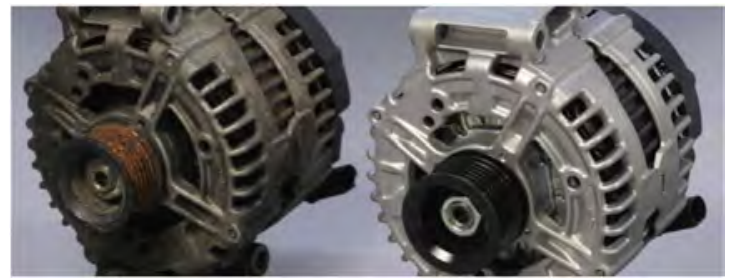

Fig. 4. Example of core and remanufactured product.

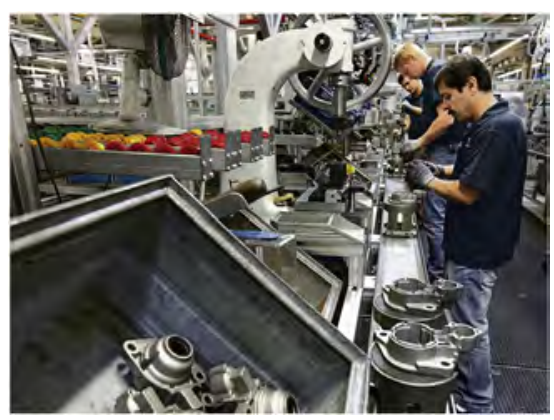

Fig. 5. Remanufacturing line in Krakovets, Ukraine. 
considered in the design of new products. In addition, Bosch transferred its expertise on reverse logistics into an independent subsidiary Circular Economic Solutions $\mathrm{GmbH}$, offering reverse logistics as a service as well as consulting. The major issue is represented by the high variety of returned products that affects the possibilities for advanced automation in the remanufacturing processes. From the technical point of view, the identification of the used returned part and the subsequent clustering is the missing link between the reverse logistics and the development of more efficient remanufacturing processes.

French car manufacturer Renault is actively contributing to the development of the Circular Economy. Amongst its numerous initiatives, the Group is a founding member of the Ellen MacArthur Foundation. From 2008, a wholly owned subsidiary, Renault Environment, coordinates a large part of the Group's Circular Economy activities. Renault is the only European carmaker to have taken shares (50\%) in companies that recycle End-of-Life Vehicles (ELVs), such as Indra, a French specialist in vehicle dismantling and parts recovery, and Boone Comenor, that manages ferrous and nonferrous metallic waste at Renault sites. The recovery of end-ofseries vehicles at plants and after-sales warehouses is managed by the wholly-owned subsidiary, Gaia. The vision of Jean-Philippe Hermine, Head of the Environmental Plan of the Renault group, says a lot about the Group's commitment: "Detecting potential resources in end-of-life products and safeguarding their technical and economic value is a new, and virtuous, way of sharpening your competitive edge. Who is better able than the producer of the goods and corresponding services to control these resources, ensure their quality and traceability, and make optimum use of them?". Renault's plant in Choisy-le-Roi, near Paris, remanufactures automotive engines, transmissions, injection pumps, and other components for resale (Fig. 6). The plant's remanufacturing operations use $80 \%$ less energy and almost $90 \%$ less water, as well as generate about $70 \%$ less oil and detergent waste, if compared with new production. Remarkably, the plant delivers higher operating margins than Renault as a whole can boost.

To facilitate end-of-life practices, the company redesigns certain components to make them easier to disassemble and reuse. The design of Renault vehicles includes constraints linked to dismantling and recycling and considers closed-loop reuse options, achieved by converting materials and components from worn-out vehicles into inputs for new vehicles.

Renaults contributes to the collection and processing of the $25 \%$ of the total ELVs in France through Indra, operating a network of 400 dismantlers processing more than 95,000 vehicles in 2015 . The experts of Indra developed and industrialised advanced engineering applications helping the dismantlers to optimise the dismantling process planning, to organise the disassembly lines and to take optimal decisions concerning the inventory of spare parts. The dedicated software was developed to guarantee traceability throughout the chain and the technical identification of reusable parts intended for resale. The experts of the company are also involved in collaborative projects such as VALVER (glass recycling), VALTEX (recycling textiles and foam), and PAREO (recycling engineering plastics and polyamides). Through these innovations, INDRA can reach a target dismantling time of three hours per vehicle, ensure the daily breakdown of $25 \mathrm{ELV}$ s at each site and met in 2015 , the objective to recycle $95 \%$ of vehicle mass.

One of the major challenges is to optimise the transportation of the materials to be recycled. Indeed, some technically recyclable

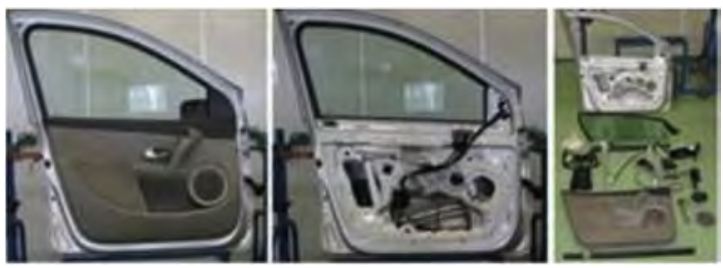

Fig. 6. Car door disassembly and remanufacturing. materials are not processed because of high transportation cost. By sharing the transportation between materials having high and low recycling profits, one can expect improving the overall recycling rate. Another technological challenge is the development of new dismantling procedures for hybrid and electrical vehicles and the establishment of a proper recovery network for the used batteries. From the business perspective, the challenge is the estimation of the return rates of particular models of vehicles in order to optimise the inventory and revenue management.

Airbus, a leading aircraft manufacturer, estimated that annually more than 200 aircraft will be retired from their service in the coming years. For this reason, in 2005 Airbus launched the PAMELA project "Process for Advanced Management of End-of-Life of Aircraft". The key achievements of this project were threefold. Firstly, a full-scale experimentation demonstrated that $85-95 \%$ of aircraft components could be easily recycled, reused or recovered. Secondly, the project set up a new standard for safe and environmentally friendly management of End-of-Life Aircraft (ELA). Finally, the project launched a European network for dismantling processes. During the project, the consortium created a three-steps approach for handling End-of-Life Aircrafts, 3D approach, including D1-decommissioning, D2-disassembly, and D3-smart dismantling. The process was demonstrated on an Airbus A300, as shown in Fig. 7.

In the decommissioning phase, the aircraft is inspected, cleaned and decontaminated. During the inspection, a detailed list of aircraft parts that could be disassembled and reused is prepared. This ensures that the aircraft parts can be traced through the complete end-of-life phase. Furthermore, all operating liquids are removed and either re-sold for direct reuse or disposed of in specific recovery channels, according to the existing regulation. Besides operating fluids, hazardous substances also need to be removed and disposed of, e.g. depleted uranium.

In the disassembly phase, the owner of the aircraft may decide to refurbish it by repairing and/or replacing defective equipment and parts. Otherwise, the End-of-Life Aircraft enters the irreversible disassembly process in which all the equipment and parts that can be reused are removed. Re-usable and disassembled parts are usually engines, landing gears, avionics, Auxiliary Power Unit (APU), Ram Air Turbine (RAT), as well as parts of the cabin equipment. For the selected parts, the geometry, the exact position in the aircraft as well as technical information, materials and connections to other parts are gathered. This information is used to create a disassembly sequence. Disassembly sequence planning includes a detailed scheduling of the disassembly tasks and the shop floor control.

The smart dismantling phase takes into consideration best practice recommendations and full compliance to applicable regulation. Aircraft mapping in the smart dismantling phase is considered as a fundamental step to identify accesses and zoning. The material fractions are precisely identified, among them aluminium, steel, titanium, and composites. A 14-step procedure was conceived consisting of dividing the airframe into sections, separating the wings from the fuselage, sorting different materials, grouping the materials for recovery, preparing the structure for shredding and smelting. In summary, the project designed a generic methodology applicable to any kind of commercial aircraft, identified best practices recommended to ELA industry platforms, provided feedback of lessons learnt to design offices, and demonstrated the need for establishment and further develop-
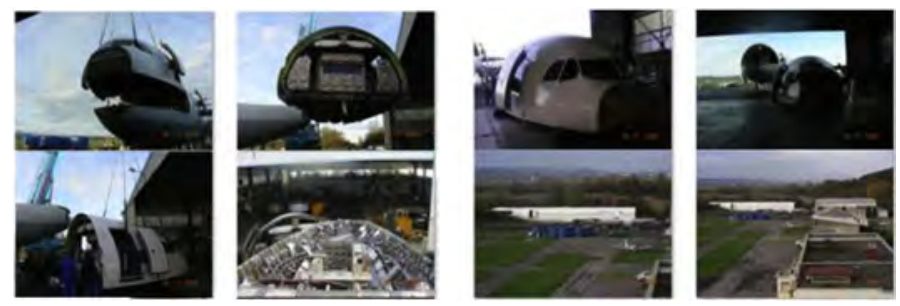

Fig. 7. Airbus EoL process. 


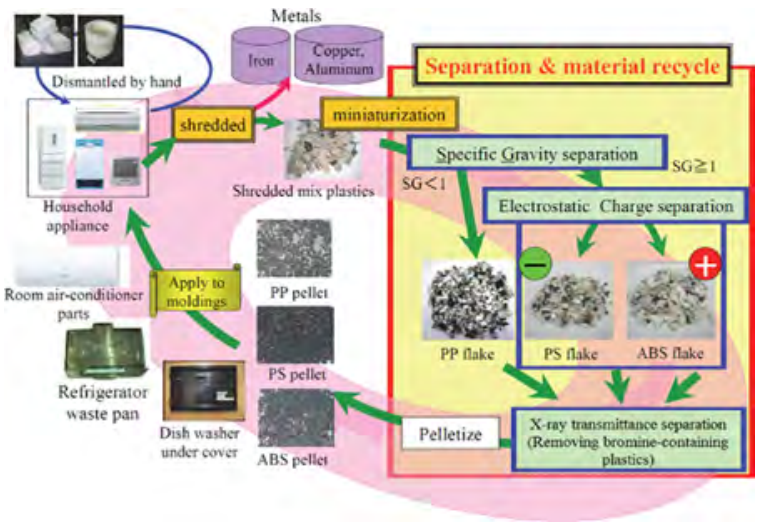

Fig. 8. Closed-loop high-purity plastic recycling system.

ment of a hybrid reverse supply chain. As a result, the possibility to increase the ratio of value creation up to $80-85 \%$, the reuse and recycling ratio up to $70 \%$, and to reduce landfilled waste down to $15 \%$, against the current $40-45 \%$, was shown.

Following the enactment of the home appliance recycling law in Japan in 1998, Mitsubishi Electric Corporation started its electric appliance recycling business in 1999. Later, in 2010, the company introduced a large-scale high-purity plastic recycling system, enabling closed-loop recycling of shredded plastic mixtures (Fig. 8) [93]. With this system, the company secured a stable supply of high quality plastics, with reasonable cost for producing new home appliances. It was also important for Mitsubishi to elevate the brand value by exhibiting their initiatives for efficient and effective resource utilisation.

Plastic recycling makes up a significant part of home appliance recycling. Conventional closed-loop plastic recycling is, however, limited to large size plastic parts with a single material, which can be easily disassembled. However, such plastic parts only account for about $10 \%$ of all plastic used in home appliances. The remaining $90 \%$ of plastic has to be shredded into a plastic mixture containing many kinds of plastic and small metal fractions, which can only be used for thermal recycling.

The high-purity plastic recycling system has enabled Mitsubishi to recover polypropylene (PP), polystyrene (PS), and acrylonitrilebutadiene-styrene (ABS) flakes from a shredded plastic mixture, with a over $99 \%$ purity. These three kinds of plastic account for $70 \%$ of the plastic used in home appliances. The company developed a separation process consisting of specific gravity separation, electrostatic charge separation and X-ray transmittance separation for removing the plastic flakes with a bromine flame retardant content, as shown in Fig. 9.

To implement such a recycling system, the company had not only to develop new separation technologies but also a specific circular chain, compliant with the current home appliance recycling law. The key issues include a stable supply of used products as raw material and the market, whose demands have to be met by the recycled material in terms of quality, price, and volume. Therefore, the company had to verify whether the entire chain could work before starting the recycling business. The company still faces the challenges of continuously improving the system for adapting to variations in product design, leading to changes in material mixtures, and to new legislation.

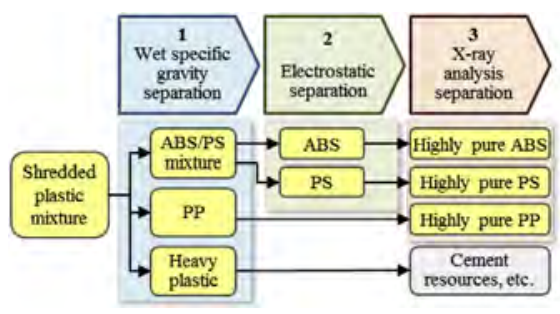

Fig. 9. Mixed plastic recycling process
The reported industrial cases support these considerations:

- Circular Economy is already a profitable business opportunity for manufacturers in different sectors.

- The implementation of Circular Economy businesses provides substantial social and environmental benefits.

- The application of Circular Economy businesses is not in contrast but, in fact, is highly synergic with new product manufacturing operations.

- De- and remanufacturing solutions are applied both in small and large volume scenarios, where a trend towards increased automation levels is observed, aiming at cost efficiency.

- Uncertainties in product returns and market demand are the major causes of complexity in de- and remanufacturing systems, with respect to manufacturing systems [60].

- Product information plays an important role in the decision making process about de- and remanufacturing operations, and this feature provides competitive advantage to the manufacturer in the implementation of circular businesses.

- The role of advanced de- and remanufacturing technologies and systems is fundamental to achieve the required quality and efficiency of the regeneration process.

- The profitability of the business is strongly influenced by manufacturers' product design decisions.

- A value-chain and business model reconfiguration may be needed while shifting to new Circular Economy businesses.

\section{Reference framework for de- and remanufacturing}

Several frameworks have been introduced in the literature to highlight the main features of Circular Economy. For example, in Ref. [175] a diagram characterised by multiple closed loops corresponding to different Circular Economy options and taking into account the flows of technical and biological materials, is presented. Other models, such as those proposed in Refs. [54], [100], and [277], are less specific in the representation of the material flows and mainly concentrate on the Circular Economy options, in interaction with the traditional linear product life-cycle phases.

Although these models are useful to explain the Circular Economy concept in a product life cycle perspective, they fail in highlighting the de- and remanufacturing related operational implications for manufacturers while introducing a Circular Economy business. Moreover, they do not highlight the role of the involved stakeholders and the flow of information along the valuechain. However, as denoted by the real cases presented in Section 1 , the modern implementations of Circular Economy business models rely on the strong involvement of the product manufacturer. This emerging vision goes beyond the principle of Extended Producer Responsibility (EPR), on which most of the existing legislations ground, which is at the basis of traditional open-loop material recycling businesses. To overcome this limitation a new framework is proposed in this paper and presented in the next paragraph.

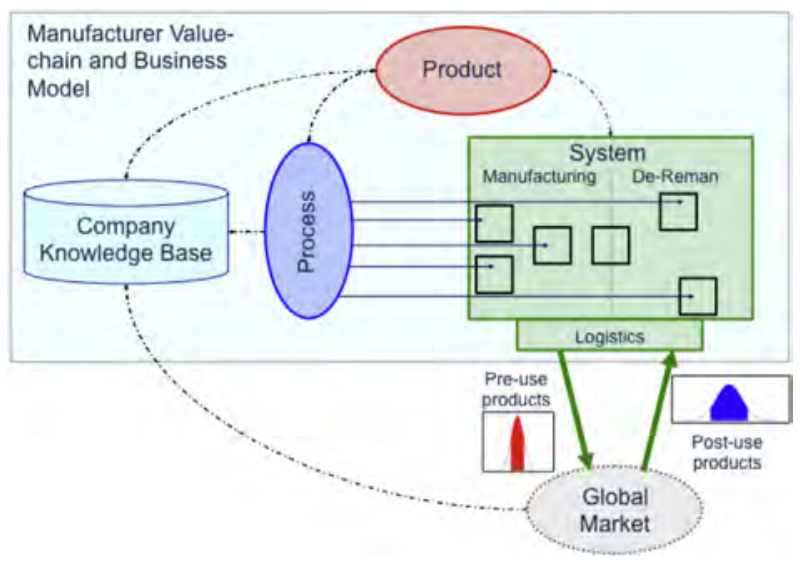

Fig. 10. Manufacturer-centric Circular Economy framework. 


\subsection{Manufacturer centric Circular Economy framework}

The proposed manufacturer-centric Circular Economy framework is represented in Fig. 10. It grounds on existing manufacturing frameworks and extend them to meet the vision of modern Circular Economy business scenarios. The baseline model is the one proposed in a past CIRP keynote paper dealing with the coevolution of products, processes and production systems in manufacturing [268]. The main idea introduced in that framework was the need to match the dynamics of the product, process and system life-cycles in order to improve manufacturing performance in highly changeable and unpredictable market contexts. To achieve this goal, a co-design and coordinated evolution management of products, processes and systems were advocated, and specific tools and methods to support these objectives were revised. Starting from the same basic considerations, in this paper we extend the concept to de- and remanufacturing operations and post-use products.

The framework highlights four major phenomena. Firstly, focusing on the "System" element of the product, process, and system triangle, the manufacturing and de- and remanufacturing operations are represented in this new model as integrated. Although the related processes may not be physically located in the same plant and, in some cases, may be applied by different stakeholders in the value-chain, considering these systems in a synergic way is at the basis of modern industrial implementations of Circular Economy. For example, referring to the Knorr Bremse case, while disassembly and remanufacturing operations are carried out in a dedicated plant, the reassembly operations are carried out in the same assembly line used for new products. This is due to the need of avoiding replicating investments in expensive product inspection equipment. In this case, the synergy is exploited within the same company, but in different production sites. Another example is related to the Mitsubishi case: the deand remanufacturing operations and the production of new components take place "under the same roof" in order to exploit locally root cause analysis and quality assurance procedures. Finally, in the Renault case, joint-ventures with specialised companies are created to implement de- and remanufacturing operations, exploiting the availability of the product knowledge provided by the manufacturer. As these examples show, integrating manufacturing and de- and remanufacturing operations is an effective way for reducing the cost of shared equipment, for exploiting product knowledge during the de- and remanufacturing processes and to achieve improved quality.

In fact, manufacturing and de- and remanufacturing objectives are clearly not independent. The products that are manufactured and sold to the market today are the products that will be collected and processed in input at the de- and remanufacturing system after the customer use phase. As a consequence, the rapid introduction of new products and the increasing product variety in manufacturing is reflected in the continuous evolution of postuse products collected from the market. In addition, the use-phase introduces variability and uncertainty in the conditions of these post-use products. Such variability needs to be smoothed by the de- and remanufacturing system, in view of delivering a regenerated product that is of comparable quality with respect to the new product. In the proposed framework, this second aspect is represented by an increased variability of post-use products collected from the market, with respect to pre-use products.

The third key aspect reflected in this model is the information flow, represented by interrupted lines between the different elements, which creates and enriches the manufacturer knowledge base, in a continuous learning perspective. Two major information flows are relevant. The first flow makes the product design information available to the manufacturing and de- and remanufacturing system. This information is useful especially in the context of complex products, were managing product information is a valuable asset for better targeting de- and remanufacturing operations. For example, the widespread use of embedded software and system integration in mechatronics

makes product information availability a strategic resource for remanufacturers in the automotive market, due to the complexity of diagnostics and testing. The second flow refers to the gathering of information from the product use-phase back to the manufacturer. This information is useful for better understanding the condition of post-use products and adapting de- and remanufacturing decisions and operations accordingly.

The fourth key aspect of the model is the consideration of the company value-chain and business model. It acts as a "higher level controller", defining targets for the manufacturing and de- and remanufacturing operations as well as the specific allocations of activities to different stakeholders in the value chain. It defines the mechanisms for delivering added-value functions to the customers, also considering a product-service [188] perspective.

Bringing the concepts represented in this framework to the boundaries, the idea of Circular Factory emerges [128,263]. Considering the environmental load and resource consumption of the product life cycle, the role of manufacturing should be to provide people with the functions that are realised by products rather than with products themselves [277]. In this sense, it should not be discriminated between newly produced and second-use products, as long as they provide the required functionality. The circular factory should be a sort of "purification and enhancement system" that circulates resources in effective and efficient ways, smoothing the product variability, with minimal environmental load. New resources are acquired only to replenish a deficiency or to apply enhancements in the system. The circular factory should perform both manufacturing and de- and remanufacturing operations, exploiting the synergies among them and the knowledge on the product conditions, to improve the business profitability along the entire product life-cycle.

\subsection{Specific challenges for de- and remanufacturing systems}

As highlighted by the analysis of the real cases, the realisation of a modern manufacturer-centric Circular Economy model poses several challenges on de- and remanufacturing systems [235,7,254]. These challenges are summarised in Table 1.

The trend towards an increased product variety [59] and a fast rate of product model substitution in manufacturing translates into a need for specific forms of flexibility [267] and reconfigurability of de- and remanufacturing systems. Furthermore, the high level of variability of the post-use product conditions requires adaptability of the de- and remanufacturing system as well as solutions for data gathering and data management. This would also support a controlled supply of return products to the system, which is pre-condition for the Circular Economy business profitability. Not only the input product, but also the market value of the output product, component, or material, is affected by

Table 1

Challenges for de- and remanufacturing systems.

\begin{tabular}{|c|c|}
\hline Global trends & Challenges \\
\hline $\begin{array}{l}\text { Short life-cycle of products and high } \\
\text { product variety }\end{array}$ & Flexibility and reconfigurability \\
\hline $\begin{array}{l}\text { High variability in the conditions of } \\
\text { post-use parts }\end{array}$ & $\begin{array}{l}\text { Variability of process sequences and } \\
\text { processing times }\end{array}$ \\
\hline $\begin{array}{l}\text { Poor information about return } \\
\text { products }\end{array}$ & $\begin{array}{l}\text { Need for Information and } \\
\text { Communication Technology (ICT) } \\
\text { solutions and big data management } \\
\text { Need for in-line part and materials } \\
\text { inspection }\end{array}$ \\
\hline Increasing product complexity & $\begin{array}{l}\text { Need for knowledge-based tools } \\
\text { Involvement of the manufacturer }\end{array}$ \\
\hline High fluctuation in materials' value & $\begin{array}{l}\text { Emphasis on business models, } \\
\text { inventory and production planning }\end{array}$ \\
\hline Pressi & Need for hybrid automation solutions \\
\hline $\begin{array}{l}\text { Increasing quality requirements on } \\
\text { recovered materials and } \\
\text { components }\end{array}$ & $\begin{array}{l}\text { Need for process automation, } \\
\text { repeatability and quality assurance }\end{array}$ \\
\hline $\begin{array}{l}\text { Increasing attention on safety and } \\
\text { ergonomics }\end{array}$ & $\begin{array}{l}\text { Need for human-centric design of } \\
\text { disassembly and sorting workstations }\end{array}$ \\
\hline
\end{tabular}


high variability and fluctuation in Circular Economy businesses. Such uncertainty generates pressure on the development of robust inventory and production planning tools, able to maintain the business model effectiveness during the operational phase. The continuous pressure on operational costs reduction and the strict customer requirements on the quality of the regenerated products or materials pose specific challenges on the efficiency of de- and remanufacturing processes. This trend calls for advanced automated and semi-automated solutions, able to combine high efficiency and quality in operations. Finally, the increasing pressure on operators' safety and ergonomics requires new human-centric designs of de- and remanufacturing systems, especially in process stages with high manual work contents.

\subsection{Requirements for de- and remanufacturing systems}

The aforementioned challenges put the basis for the development of a next generation smart de- and remanufacturing systems characterised by (i) high adaptability to the product and market conditions, (ii) high level of automation, (iii) availability and traceability of information, (iv) high safety and ergonomics levels in human-centric environments, and (v) managed by advanced decision support tools based on data analytics, distributed data gathering and cyber-physical systems. While these concepts have been investigated in the manufacturing system community, establishing the basis for the modern concepts of smart manufacturing and Industry 4.0, they have been addressed in the de- and remanufacturing area by a less structured approach.

In line with the requirements analysed in the previous sections and with respect to the innovative manufacturer-centric Circular Economy model, the remainder of this paper is dedicated to a systematic review of the state-of-the-art methodologies, tools and enabling technologies that represent the fundamental building blocks for the smart de- and remanufacturing systems of the future. More than 300 papers in the field have been revised and framed with respect to the proposed framework. They will be presented starting from process and technological characteristics, in Section 3, continuing with the methods for planning and control de- and remanufacturing considering product and market implications in Section 4, and concluding with de- and remanufacturing systems design approaches in Section 5.

\section{De- and remanufacturing processes and emerging enabling technologies}

With the objective to recover and upgrade functions and materials in complex products, de- and remanufacturing systems are usually multi-stage, integrating different processing stages. In this section a simple taxonomy of de- and remanufacturing processes is proposed. They represent the fundamental components of de- and remanufacturing systems that need to be properly integrated in order to provide the combined capability to the system. The goal of this taxonomy is the positioning of each process in a typical de- and remanufacturing stage, highlighting its function and its scope. For each process, the most promising physical and digital emerging technologies towards smart de- and remanufacturing systems of the future are revised (Table 2).

Table 2

Emerging enabling technologies.

\begin{tabular}{ll}
\hline Process stage & Emerging enabling technologies \\
\hline Materials and functions & Automated disassembly via cognitive robotics; \\
liberation & human-robot cooperation; active disassembly \\
Sorting and separation & Automatic sorting; robotic sorting \\
End-recovery & Solid-state recycling \\
Inspection & Hyper-spectral imaging; multi-sensor systems; \\
& embedded sensors; Internet of Things (IoT) \\
Reconditioning & Additive manufacturing; hybrid additive and \\
& subtractive technologies \\
Logistics & Flexible and reconfigurable automation; \\
& distributed control; Cyber-Physical Systems \\
\hline
\end{tabular}

\subsection{Materials and functions liberation processes}

Material and product function liberation processes are usually the first stages of a de- and remanufacturing process-chain. They include disassembly and size-reduction processes.

Disassembly is performed with the scope of isolating (i) hazardous components that should not enter the de- and remanufacturing flow, (ii) re-usable parts with high residual value, (iii) parts that need to go through a dedicated process-chain. Disassembly makes it possible to achieve product function recovery, high material-return rate, and pre-concentration of waste. However, it is usually an expensive process due to the difficulty of the tasks and the demand for manual labour. Disassembly processes have been classified into three categories, namely destructive, semi-destructive and non-destructive [288]. In non-destructive disassembly all the output components remain undamaged. This is desired for maintenance, reuse and remanufacturing. In semi-destructive disassembly, only connective components are destroyed, e.g. via breaking, folding or cutting, leaving the main components with little or no damage. Destructive disassembly deals with the partial or complete destruction of obstructing components (e.g. welds). In general, destructive processes, sometimes called dismantling, require reduced costs and times with respect to non-destructive processes. The definition of the disassembly mechanism to be adopted for a specific product depends on the (i) type of joint, (ii) type of material, (iii) required performance and (iv) target automation level. A classification of specific disassembly operations in relation to these factors is reported in Ref. [239]. Moreover, specific tools to support disassembly operations are classified in Ref. [296].

Disassembly is one of the key steps for efficient treatment of post-use products [223]. However, the process may become economically infeasible due to high labour costs, especially in high-wage countries [54]. Therefore, automation could be a possible solution for cost-effective disassembly. Other reasons of interest for this area are the attempt to increase the level of quality and standardisation of the process and the need of increasing the workers' safety by reducing the risk of contact with hazardous materials. However, uncertainties and variations in returned postuse products are significant sources of problems for disassembly process automation. Automated disassembly solutions have been developed to deal with specific applications. Examples are reported in Refs. [54] for washing machines, [154] for mobile phones, in Ref. [269] for PCs, in Ref. [294] for traction batteries and in Ref. [101] for lithium-ion batteries. In these applications, the ability to deal with various models of products automatically is still limited, since a priori information regarding product models needs to be supplied. In order to address this problem, an emerging approach based on the concept of cognitive robotics together with learning was recently proposed [286,285]. Fig. 11 shows the architecture of this solution. In this approach, the concept of cognitive robotics is used to emulate the behaviour of human operators and is capable of handling the uncertainties in the disassembly process. As a result, the system is able to deal with any models of products and variable conditions without supplying specific information regarding products and operations.

In order to combine the requirements for automation, flexibility, and human ergonomics and safety, the idea of designing hybrid disassembly systems based on human-robot cooperation and cognitive robotics has also been recently proposed. Humanrobot Cooperation (HRC) is an emerging paradigm in manufacturing aiming at safely sharing the working space among robots and operators in performing complex and physically demanding tasks [159]. The introduction of human-robot collaborative cells in disassembly enables a re-allocation of tasks among the human and the robot, increasing human satisfaction and comfort. The robot will execute all the majority of low value tasks (e.g. screwing or unscrewing), while the human will maintain high value tasks through which knowledge can be valorised (e.g. extraction of delicate/valuable components). Moreover, human ergonomics can 


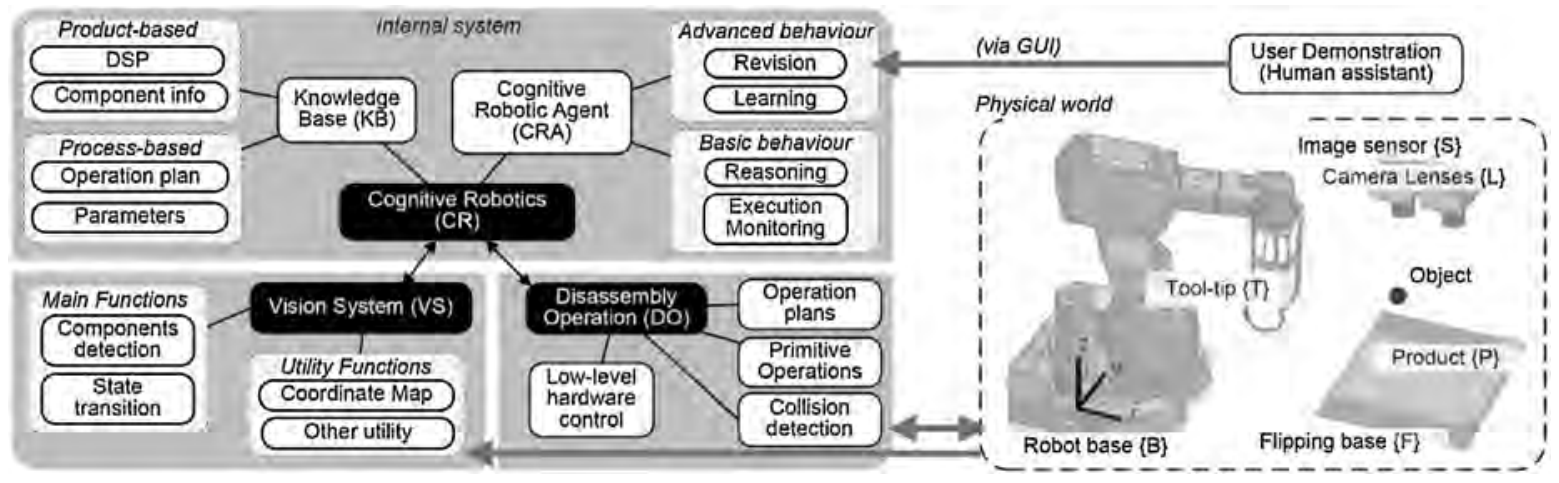

Fig. 11. Cognitive robotics architecture for disassembly [285].

be improved, using the robot as a holder able to quickly reorientate in the space the workpiece to be disassemble in support of the human task that is in execution. A first example of humanrobot cooperative plant for mechatronics disassembly for remanufacturing is presented in Ref. [46]. Despite the advantages deriving from the introduction of human-robot collaboration in disassembly systems, several technological and scientific barriers can be identified. The first barrier is represented by safety norms that have to be considered when the paradigm of separation between humans and robots cannot be applied. The technical specification ISO/TS 15066 [118] is ready for providing implementation guidelines [181]. The second barrier is represented by the lack of industrially exploitable methodologies able to study human intention and to plan the robot motion in order to increase human comfort and reduce the stress induced in the human by the collaboration with a robot [12]. Risk perception and cognitive workload are gaining increasing consideration in both research and industrial communities [190].

Another relevant enabling technology in this area is the development of reversible and detachable joints for active disassembly. In manual disassembly localizing fasteners typically accounts for one to two thirds of the disassembly time depending on the product category $[53,210]$. Visual localisation is also in conflict with the trend towards miniaturisation and the increasing aesthetics requirements for many categories of products. In response to these observations, active fasteners, that can be externally triggered without requiring individual localisation and access, have been developed. A summary of the state-of-the-art solutions is shown in Table 3.

A range of research efforts towards active disassembly has been focusing on temperature sensitive fasteners based on shape memory materials [40,199]. However, commercially available temperature sensitive fasteners are conceived as tapes containing thermoplastic expandable microspheres that encapsulate a hydrocarbon liquid which gasifies and expands when exposed to heat $[19,140]$. Furthermore, pressure sensitive fasteners, equipped with a cavity that contracts when the ambient air pressure increases, were patented [157,224]. The embodiments of these fasteners were optimised by means of 2D topology optimisation in Refs. [300] and [301]. More recently, a number of small-scale pressure sensitive active fastener designs, using closed-cell elastomer foams, were developed and their robustness has been

Table 3

Fasteners for active disassembly [211].

\begin{tabular}{|c|c|c|c|}
\hline Trigger & Temperature & Pressure [210] & Impulse [212] \\
\hline $\begin{array}{l}\text { Working } \\
\text { principle }\end{array}$ & $\begin{array}{l}\text { Phase change } \\
\text { materials }\end{array}$ & $\begin{array}{l}\text { Compression of } \\
\text { closed-cell foam }\end{array}$ & $\begin{array}{l}\text { Damping by } \\
\text { elastomer }\end{array}$ \\
\hline Example & 1 W Comsonert A & a corsonents & 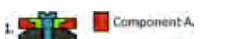 \\
\hline $\begin{array}{l}\text { Required } \\
\text { installation }\end{array}$ & Oven & Pressure room & $\begin{array}{l}\text { Manual disassembly } \\
\text { station }\end{array}$ \\
\hline
\end{tabular}

demonstrated in electronic equipment applications [212]. Also, low-cost elastomer fasteners have been developed that can be released with standard disassembly tools by applying a sufficiently high force over a sufficiently long period of time, typically around one second [282]. The concept behind these elastomer-based fasteners is that they will not release but only deform to a limited extent during a product drop, since the elastomer will absorb the released energy. When the impulse is sufficiently high, for example by placing a lever between the attached components with maintained force, the elastomer-based fasteners will deform and subsequently release [212]. These fasteners have been validated to allow reducing disassembly times by $70 \%-90 \%$ for the housing of LCD TVs, without compromising product robustness [211].

The scope of size-reduction, or comminution, processes is substantially different from disassembly processes. Their goal is to (i) break large elements or particles composing a mixture into smaller fractions and, by doing so, to (ii) liberate inhomogeneous or mixed material particles. Size reduction processes are therefore applied in favour of improving the feasibility and quality of the downstream separation processes. Differently from disassembly, size-reduction is always a destructive process.

Size-reduction processes are characterised by a cutting mechanism that induces a mechanical stress, that can be compressive, tensile or shear stress, on the particles through the action of one or more cutting tools. The fundamentals of size-reduction processes date back to classical minerals processing [241]. Even if the applied treatments are similar, or the same in some cases, it was learned that the breakage and liberation behaviour of consumer products differs fundamentally from that of mineral ores. The main reason is related to the presence of joints, usually of different materials with respect to the joined parts. According to Refs. [281], [229] and [283], the degree to which the different connected materials are liberated to mono- and multimaterial particles during size-reduction is determined by the following design properties:

- The combined material properties (e. g. brittle, ductile) of the connection/product/component.

- The type of the material joints and connections.

- The characteristics of the joint, e. g. size of the connections in relation to particle size distribution after shredding.

- Complexity and homogeneity of the components connections (e. g. spatial distribution of the connections in the product, number of materials connected per connection).

- The thermodynamic compatibility among metals, alloys and metal compounds.

Typical size-reduction processes involve grinding, shredding or pulverizing stages and can be performed as wet or dry processes and at controlled temperature. Different size-reduction mechanisms and technologies include hammermills, granulators, cutting mills, shearing cutters and cryogenic mills. These machines are usually fed top-down and the output particle size may be controlled by a meshed grid. Due to the weak control of the particle geometries in output and the presence of multi-material joints, the output particle size in size-reduction processes is always 
a random variable. It mainly depends on static parameters (the kind of process, the number and geometry of tools, etc.), dynamically controllable parameters (shaft speed, grid size, etc.), and specified parameters (the composition of the input stream, the rate of flow, etc.). Typical limitations concern the energy consumption, which is a function of the degree of size reduction, and the tool wear. These are major factors determining the operational process costs. For reviews of size-reduction processes and the related machines see Refs. [178] and [102].

\subsection{Sorting and separation}

The scope of sorting and separation stages is to split a mixed input material stream into two or more output streams in which the concentration of target products, components or materials is greater than in the input stream. Separation is usually performed by a series of stages involving different technologies that classify materials on the basis of their properties. For typical incoming mixtures, multiple separation stages may be needed for (i) exploiting different properties to separate in sequence different materials at high grade or (ii) for repeating the same process to increase the recovery/grade of the required material in the interesting flows. The most common mechanical, or physical, material separation processes use the following material properties for the classification: particle size and shape (tilted plate, sieves), magnetic susceptibility (magnetic separation), electric conductivity (eddy current, corona electrostatic, and triboelectric separation), density (gravity separation, floatation, jigging, hydrocyclone), colour, light reflection spectra, transparency (automatic optical sorting). For reviews of physical separation processes see Refs. [51] and [302]. A separation process creates an environment in which particles with a high value of the property move differently from those with a low value of the property. Random disturbances make the result of actual separation processes subject to inaccuracy and errors. This causes the contamination of the output flows, where materials are wrongly classified. For this reason, physical separation processes are usually adopted in the early stages of a process-chain for an initial sorting of streams. They prepare the materials for the end-refining treatments.

One of the most promising emerging enabling technologies is automatic sorting. This technology has been widely diffused in the last decades to separate different types of plastics, stainless steel from metals, and glass. The basic components of these systems are (i) the sensor array, which identifies the material, (ii) the material identification software, (iii) the transportation module, and (iv) the actuation system, for sorting after identification. Since they combine high capacity and high separation quality, these systems are becoming more and more common in mechanical de- and remanufacturing systems for material recovery. One of the major limitations is, however, the actuation system. Usually, it is based on arrays of fixed ejectors, which use compressed air to deviate the particles to be sorted. Being customised on specific particle sizes and material densities, the actuation module is usually poorly reconfigurable for different mixtures and it needs to be replaced in case of considerable changes in the material properties, due to a product change. Recently, flexible robotic sorting systems have been proposed and industrially applied, especially for coarse particles and entire sub-assemblies. Successful applications are found, for example, for construction waste [172]. These actuation systems are extremely flexible and may constitute a relevant technological enabler towards smart de- and remanufacturing systems. Various material sizes and compositions can be handled by combining modifications in the robot control and grippers.

\subsection{End-recovery}

End-recovery processes make use of chemical-thermal processes to separate the target materials, usually metals, at very high grade levels. They take in input pre-sorted mixtures and apply batch processes to purify the target materials to be ready for post- recovery use. Among the most effective end-refining processes hydrometallurgical [64], pyrometallurgical [142], electrometallurgical and biometallurgical [111] processes, and their combinations, represent the most common options. Hydrometallurgical and pyrometallurgical processes are the major routes for high-tech waste such as electronic and automotive waste. In hydrometallurgical processes the isolation of metals of interest is conducted through solvent extraction, adsorption and ion exchange enrichment processes. Finally, metals are recovered from solution through electrorefining or chemical reduction processes. In pyrometallurgical processes the liberation and purification of valuable metals are achieved by smelting in furnaces at high temperatures. In these processes, metals are sorted by exploiting their chemical and metallurgical properties. Although environmental benefits are achieved through hydrometallurgical processes, pyrometallurgical plants are more widely installed at industrial level, due to the fact that hydrometallurgical reactions are slow, time consuming and may impact the economic performance of the process. For reviews of end-recovery processes see Refs. [281], [50] and [14].

Solid-state recycling has been proposed as a viable and ecoefficient alternative to metallurgical processes for end-refining and re-production of light metals in bulk as well as sheet components. The recovered material is treated by means of plastic deformation and directly formed into the final product. The main advantage of this technology is the avoidance of fusion of the material through the use of cold or hot re-forging, re-forming and powder metallurgy technologies. The drawbacks are the need for highly pure recovered input materials, which makes solid-state recycling applicable mainly to industrial scraps and chips formed during metal cutting processes. Recent studies have shown that, if technically feasible, this process outperforms traditional metallurgical processes in terms of economics and environmental performance, making the process feasible also for small lot productions [56]. A review of processes and technologies for solid-state recycling can be found in Ref. [245].

\subsection{Inspection}

Inspection processes are applied in de- and remanufacturing systems at different stages, for several purposes. Different types of applications are found in material characterisation during recovery processes and in product functionality assessment during remanufacturing processes. Concerning applications in recovery processes, the goal of inspection is to gather information about the composition, the particle shape and size of the mixture under treatment. Applications are usually off-line and require sample extraction, preparation and measurement execution. Typical technologies for this purpose are Inductively Coupled Plasma - Mass Spectrometry (ICP-MS), Inductively Coupled Plasma - Optical Emission Spectrometry (ICP-OES), Scanning Electron Microscopy (SEM), X-Ray Diffraction (XRD) or X-Ray Fluorescence (XRF). The collected off-line information is useful for mixture value and quality assessment but cannot be exploited for process control. With the objective to provide intelligence to de- and remanufacturing systems for material recovery and enable their adaptability to different postconsumer products, the application of in-line material characterisation technologies would provide capabilities for (i) a full materials data storage and traceability, (ii) a remote monitoring and control of the processes, and (iii) an easy reconfiguration of the system. Indeed, it would enable the recycler to have a continuous visibility of the material under treatment, gathered in-line and during the process, thus avoiding expensive and time-consuming off-line sampling material characterisation procedures.

HyperSpectral Imaging (HSI) technologies have been proposed as promising solutions. Also known as Spectroscopic Imaging and originally developed for mining and geology, HSI has now spread into different fields, such as pharmaceutical and food sectors, and is penetrating the recycling market, especially for the characterisation in polyolefin packaging waste [274], construction and demolition waste, and waste from electric and electronic 
equipment (WEEE) [218,219]. Imaging spectroscopy allows the simultaneous determination of the optical spectrum components and the spatial location of an object in a surface. The main advantage of this technique is related to the possibility to collect information of electromagnetic energy at each pixel of an image, with the objective to identify the target materials and evaluate their spatial distribution in the acquired image. Moreover, by combining and properly synchronizing different acquisition systems with a multi-sensor approach, multiple materials such as metals, polymers and inert materials can be jointly classified in the same mixture. HSI allows to collect a large amount of data, both spectral and spatial, for a wide set of samples in short times. However, due to the large size of hyperspectral image data, the on-line implementation of this technique in industry is challenging, requiring the use of advanced algorithms to classify materials in short time.

Concerning applications in remanufacturing processes, inspection is mainly applied at three different stages of the process chain [63], namely post-use product acceptance, part inspection, and final product testing. These stages of inspection have different objectives and technologies. The objective of core inspection is to remove parts that will be uneconomic or impossible to remanufacture. This stage is usually performed by visual inspection done by skilled operators or by simple data gathering methods, such as barcode reading. The second stage of inspection is carried out once the parts have been disassembled. It aims to identify and remove damaged, non-reusable components from the product. This stage can be performed by a combination of visual, dimensional measurements and non-destructive tests (NDT), such as magnetic particle inspection. Functional tests are also adopted in case of electronics. The third stage has the goal to assess and validate the quality of the regenerated product, before delivering it to the customer. Visual, dimensional, geometric and functional tests are adopted.

Concerning product acquisition management, innovative IT technologies such as IoT and embedded sensors can represent a revolution in the controllability of return products, affecting the profitability of the entire de- and remanufacturing business [27]. Examples [113] show that embedding sensors in the product and applying remote monitoring of its conditions can improve the ability to take strategic remanufacturing decisions, improve inventory management and production planning and control.

\subsection{Cleaning}

Cleaning is among the most demanding steps in remanufacturing and it is an essential process because the quality of the surface cleanliness directly affects the capability to perform surface inspection, reconditioning, reassembly and painting [77]. Remanufacturing cleaning is distinct from cleaning in maintenance or cleaning in new production. Cleaning in maintenance concentrates on the surroundings of the damage before repairing. Cleaning in remanufacturing is done for the whole part in order to meet the quality requirements after remanufacturing. The workpieces under cleaning in new production processes are constant in size and material, and the contaminations are mainly due to residual metal cutting fluids, lubricating oil, antirust oil, polishing paste and so on. Cleaning in remanufacturing is performed on parts that are of high variability in sizes, materials, shape and surface conditions.

Cleaning in remanufacturing has the objective to reduce contaminants present in or on a component until specified cleanliness levels have been reached. The objectives of remanufacturing cleaning in each stage of the remanufacturing process chain are different. Before the disassembly process, the goal is mainly to reduce the quantity of contaminations outside the products. The goal of cleaning after the disassembly is to detect surface abrasion, micro cracks or other failures in order to assess the remanufacturability of the product and to adjust the needed process stages according to the part conditions. The cleaning process after regeneration and before reassembly and painting is performed to remove surface machining contaminants and to prepare the surface for additional treatments. Therefore, each phase requires a specific analysis of the best techniques and methods to be applied. Four basic elements have to be considered to select remanufacturing cleaning processes: the cleaning object, the contamination source, the cleaning force/mechanism and the cleaning medium. The most common cleaning technologies can be categorised into five groups: organic solvents, jet, thermal, ultrasonic, and electrolytic cleaning. For a review of cleaning processes in remanufacturing see Ref. [170].

\subsection{Reconditioning}

Reconditioning processes are applied in de- and remanufacturing process-chains in order to restore the functionality of components after disassembly, cleaning and inspection. Depending on the part features to be reconditioned and the specific defect type, different reconditioning processes may be applied. In any case, common reconditioning processes include the following four steps [270]: (i) surface and shape defects removal, (ii) material addition and deposition, (iii) material properties restoration, (iv) surface finishing. In the first step, cracks, scratches, nicks and burrs, burnt or corroded regions, and inclusions are removed by subtractive machining processes such as turning, milling, drilling, and grinding. Surface finish and tolerances are not of top priority but rather the removal of all stress raisers. Shape defects, such as bends, warps and dimples, are also removed if technically feasible. In the second step, part with cavities and material lacks can be restored to the intended shape through additive processes, such as welding, powder deposition, laser cladding. Due to the application of high temperature, pre-heating is required to avoid cracking. In the third step, desired material properties are restored through heat treatments, which either remove unwanted residual conditions or prepare the part to be more resistant to its operating condition. High surface quality can be achieved by grinding, reaming, honing, and hard turning processes. In other cases, painting, coating by spraying processes, and polishing can be applied. For a review on reconditioning techniques see Ref. [196].

Great potential for modern part reconditioning processes in remanufacturing are provided by Additive Manufacturing (AM). AM combines the advantage of flexibility in processing free-form geometries, typical of damaged parts, and the ability of feeding different mixes of materials, thus controlling the composition of the added layer and making functional graded materials. Therefore, AM provides the opportunity to support regeneration and upgrading of part functionalities [266], for example adding a wear-resistance layer on the processed surface. Moreover, being based on a digital model of the part, it is particularly suitable for manufacturer-centric Circular Economy implementations [80]. The most widely adopted AM remanufacturing technologies are Directed Energy Deposition and Power Bed Fusion [185]. Typical examples of AM remanufactured parts are dies and molds [35]. Another example is the remanufacturing process adopted at Siemens [197] for repairing gas turbine burner tips, where Selective Laser Melting is used to reconstruct new tips after the machining process. One of the disadvantages of AM is that the surface roughness is usually not sufficient for the required remanufacturing standards. For this reason, novel potentials for remanufacturing are offered by integrated and hybrid additive-subtractive solutions. With this aim, in [198] a novel framework, called iAtractive is presented, combining additive (Fused Filament Fabrication - FFF), subtractive (CNC machining) and inspection processes on a single platform. The approach is aimed at reusing and remanufacturing existing parts or reincarnating them into new parts, with new features.

\subsection{Logistics}

Logistics processes are applied in de- and remanufacturing systems to implement spatial transformations on the products, components or material mixtures under processing. However, deand remanufacturing systems have the specific feature of being 
hybrid systems, in the sense that discrete part flows, continuous bulk processes and batch processes co-exist in different stages of the process-chain. When discrete parts need to be transported, for example in disassembly, inspection and regeneration, traditional mechanical transportation systems are adopted. However, due to the high variability of part conditions, conveyor belts or racks are typically adopted. Continuous bulk processes, or granular material flows, are found in size-reduction and separation processes. In this case, specific transportation solutions, such as closed screw conveyors or chain conveyors, can be adopted. Having internal powder aspiration systems they make it possible to safely transport granular materials, avoiding considerable losses of precious materials during transportation. Material batches are typically transported in end-refining processes. In these cases, fixed and closed material transportation systems or tanks are adopted, connecting the different reactors or smelters for the endrefining treatments. In general, state-of-the-art material transportation systems adopted for internal logistics processes in de- and remanufacturing systems are very rigid, in the sense that it is very difficult to modify the material, components or mixture routing, throughout the system life cycle. To support this function, Industry 4.0 technologies for de- and remanufacturing would constitute suitable solutions for highly reconfigurable logistics systems. For example, in Ref. [220] a suitable combination of rigid transportation modules (e.g. mechanical conveyors) and flexible routing modules (e.g. based on pneumatic systems) was proposed for granular flow routing in recycling systems. The use of hybrid pneumatic-mechanical transportation systems will allow easy implementation of new control logics whenever a significant change in the incoming products, calling for a different process sequence, is observed, or easy integration of new processing technologies if new materials have to be processed. A similar approach is proposed in Ref. [49] for supporting the adaptation of routing in electronics remanufacturing. The control system is based on the IEC61499 standard and the pallets move autonomously visiting the needed resources in the system according to locally implemented optimisation algorithms.

\section{Methods for de- and remanufacturing planning and control}

In this section, the methodologies and tools to profitably plan and control de- and remanufacturing business processes are revised. The analysis takes the point of view of a manufacturer interested in implementing a transition to a Circular Economy business. It provides practical insights on decisions and support tools to be considered for the implementation of an economically and environmentally sustainable business and the related system.

\subsection{Impact of product design on de- and remanufacturing planning}

Product design has a significant effect on de- and remanufacturing systems since it affects (i) the existing Circular Economy business options that the manufacturer can adopt [20], (ii) the selection of the related technological solutions, and (iii) the efficiency and profitability of the de- and remanufacturing process-chain [147]. By evaluating in advance the effect of product design decisions on the post-use value and function recovery processes, the manufacturer can anticipate potential issues undermining the process feasibility and implement corrective design changes towards a sustainable business development, since the early design phase of the product. This lever constitutes a unique strategic competitive asset while implementing manufacturer-centric Circular Economy businesses.

The area developing design methods to investigate the link between product design and de- and remanufacturing solutions is called Design for Life-Cycle Management [272], more specifically detailed into 'Design for Recycling', or DfR [278], and 'Design for Remanufacturing', or DfRem [98]. These could be considered as a particular set of tools and technics for design [173]. DfRem and DfR are areas of research that have received high levels of interest in the recent years. DfRem and DfR could be considered as a succession of DfX activities [34]. In DfRem and DfR research, most of the contributions are focused on the investigation of de- and remanufacturing problems associated with product design, and the subsequent development of product design methods and strategies to help reducing the impact of these issues [99]. Used inversely, these methods make it possible to adapt the definition of the de- and remanufacturing strategy depending on the characteristics of the post-use product. Within the literature, there is widespread agreement that any approach to DfRem and DfR must consider both product and process, and more widely, include a 'life-cycle thinking' vision, taking into account organisational factors affecting the integration of de- and remanufacturing considerations into the design process [277].

DfR was developed to investigate product design characteristics that affect the feasibility and profitability of recycling processes for material recovery. DfR guidelines concern many aspects of the product design. For example, specific tables are available were unsuitable coupling of difficult to separate materials are reported. The suggestion for the designer is to avoid using incompatible, in a recycling sense, materials in the same product. Another aspect addressed by DfR is the consequence of different types of fasteners on the recycling process feasibility. For example, in Ref. [281] it is shown that the knowledge about the type of fasteners adopted in the product strongly affects de- and remanufacturing system decisions. Furthermore, DfR approaches focus on the presence of hazardous materials or components and advocate to privilege product designs that favour the easy disassembly of hazardous components, at the beginning of the recycling process. Finally, the search for substitutions of suitable alternatives for critical resources and difficult to recycle materials is envisaged. Examples of recent DfR methods for complex aeronautics parts made of aluminium [164] and for composite made parts [215] showed that DfR can bring high benefits in recycling rates of critical and highcomplexity products. Specific Computer Aided Design (CAD) software tools embedding DfR capabilities have also been developed and tested on real automotive parts in Ref. [205].

DfRem has arisen as a real design approach from the recognition that many of the technical barriers to remanufacturing can be related to how the product was designed [114,115]. In DfRem, specific product properties that may have a positive or negative effect upon critical remanufacturing stages, such as disassembly and cleaning, are identified [256]. The goal is to provide designers with specific design guidelines in favour of remanufacturing options $[116,310,257]$. Guidelines concern the product materials and their coupling, the product structure and geometry, the fastening and joining methods that can support an easier and more efficient disassembly [279] and remanufacturing process [114].

Several works investigated the critical factors that make a product suitable for remanufacturing, thus influencing the feasibility of this Circular Economy business strategy. For example, Ref. [185] reports such characteristics as (i) stable product and process technology; (ii) the physical lifetime of critical components is substantially longer than the time the product is used; (iii) a product that fails functionally rather than by dissipation; (iv) a high recoverable value added in relation to the original product cost. Other pre-conditions include the existence of a market for the remanufactured product and the capability to achieve economic and environmental benefits [264].

A design methodology of great benefit for remanufacturing and reuse is modular product design [109,144,276,244], or platform design [146,200], or open architecture product [156] design. Modules are the simplest parts of a system characterised by independency (from other modules) and substitutability (with other modules). These practices enable specific standard parts that are either of high-value, made of durable materials, or of high robustness, to be reused for at least a second life-cycle. Supported by the concept of modular design, "Design for Upgradability" is a product design approach intended to easily upgrade product functions with the addition or the reconfiguration of one or more 
modules. It uses modularity to conceive products to be remanufactured and upgraded. Practically speaking, this means to design products that are easily cleaned, disassembled, repaired (through the substitution of broken modules) and upgraded (through the addiction of new modules or the change of modules). The idea of remanufacturing with upgrade is to extend products' value life enabling the introduction of technological innovation into remanufactured products in order to satisfy evolving customers' preferences and, at the same time, preserving as much as possible the physical resources employed in the process [39]. For example, in the railway industry, Meinfesa re-used EMD 645 series engine blocks and power transmission components salvaged from 333 series mainline locomotives for the construction of a follow-up sub-series 333.3 in the early 2000s. With the appearance of standard vehicle designs and interchangeable components, upcycling and re-use have gain momentum. Rebuilding practices differ from those of original construction, resulting in the emergence of enterprises that specialised in rebuilding, such as MorrisonKnudsen based in Boise, Idaho. This trend in the railway industry is aligned with the vision of a remanufacturing value chain involving several stakeholders, as outlined in Subsection 2.1. Many authors have built models or tools to define the optimal modular structure of a product to be upgraded $[217,16,246,248,158]$. Product design for upgradability may also support the diffusion of new Circular Economy business models based on the "product-service system" idea, aiming at selling the product use instead of the physical product and offering product upgradability options to customers throughout the product life-cycle $[228,216]$.

Design for product life-cycle methods are powerful enablers for the development of manufacturer-centric Circular Economy businesses through smart de- and remanufacturing systems. For example, it was shown through the analysis of specific real cases, that design for product life-cycle methods can improve the ability to automate de- and remanufacturing processes [259]. However, as a matter of fact, in spite of the wide availability of these tools in the literature, these methods have not yet massively penetrated industrial practices. The main reason is the additional cost that they can introduce in the very critical phase of New Product Introduction (NPI), were the majority of the costs and business risks are absorbed by companies. To overcome this limitation, systematic models and tools to capture life-cycle costs and profits, under a risk aware environment, should be developed to support manufacturers in this complex business evaluation.

\subsection{Post-use product return forecasting and acquisition control}

A strategic information for planning and control effective Circular Economy businesses is the estimate of product returns. In the analysis of post-use product return the underlying issue is to forecast the time when a product will be returned, the quality and the quantity of the return product as well as the demand for reused products that will be absorbed by the market. With this information the profitability of the Circular Economy business can be better assessed and relevant design and planning problems such as reverse logistics network configuration, capacity planning, facility and resource allocation, and inventory management can be formalised [42]. However, predicting product returns is a complex task due to the market uncertainties and multiple social and technological factors [94,137].

Social factors influence people's behaviour towards the disposal of malfunctioning and obsolete products as well as the reuse of regenerated products, components and materials. For example, small electronic waste, such as mobile phones, have an average life-span between purchase and disposal that is significantly longer than the average substitution time of the device [236]. The reason for this extension is the consumer behaviour: obsolete mobile phones are stockpiled at home instead of being disposed at electronic waste collection points. As frequently used in marketing research to determine customer and environmental behaviour of a population, socio-demographic and psychographic data can be

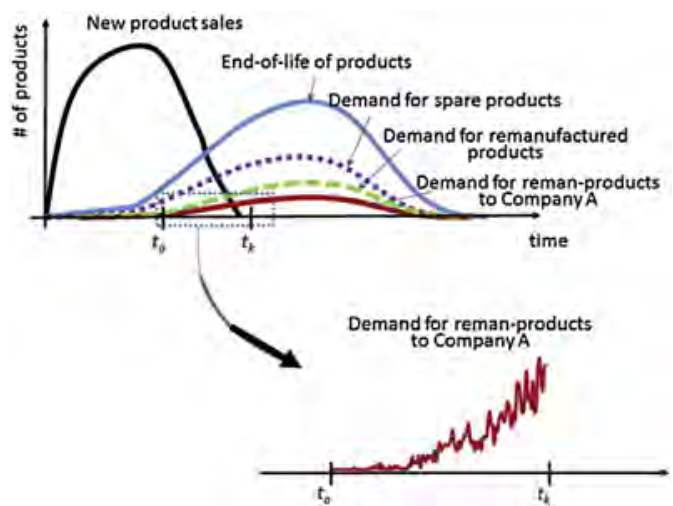

Fig. 12. Issues in forecasting return products [184].

used to represent people's behaviour in relation to de- and remanufacturing. Technological factors include technology innovation cycles, product reliability, advertising and marketing strategy. In the literature, works reporting different forecasting methods based on sub-sets of the aforementioned factors have been proposed. From the methodological point of view, they can be categorised into two approaches.

In the first approach, the time distributions of product end-of-life and product returns are calculated by adding estimates of the product use period to the time distribution of new product sales (Fig. 12). This approach has been widely used in the material recovery scenario, where aggregated product sales distributions in a target area are used, as well as in remanufacturing, where disaggregated sales data of specific components and specific manufacturers are used. Most of the models only consider the return product quantity and timing and neglect the quality aspect. Marx-Gomez et al. [180] combined simulation and fuzzy logic models to forecast the quantities and timing of returns of photocopier. Simulation was used to obtain sales, failures, usage intensity, return quotas, and other impact factors. Umeda et al. [275] proposed a model that describes the balance between product returns and demands for single-use cameras, photocopiers, and automatic teller machines based on empirical data and market sales data. Takata and Sakai [260] proposed a model for estimating the number of returned products, taking into account sales mode differences, including selling and renting modes. The consumer behaviour is included in terms of different awareness of the contract end period. The model is constructed using actual copier collection data. In Ref. [15] a method based on grey systems theory to include both precisely known data and unknown data in the forecasting model was proposed. In Refs. [95] and [96] the authors developed forecasting methodology based on fuzzy coloured Petri-nets by taking into account all the aforementioned factors. The methodology was tested in several real cases and the results demonstrated an accuracy of more than $90 \%$ in forecasting product returns. Other methods also consider the product quality condition as a factor to be forecasted. Among these, Liang et al. [169] proposed a model for predicting the return quantity, quality and timing of post-use batteries in the automotive industry. The forecasting method incorporates knowledge from sales, product usage, customer return behaviour, and product life expectancy information.

The second category is collection forecasting by time series analysis of historical data. This method has been applied to remanufacturing, in the scenario in which Independent Remanufacturers (IRs), that do not have access to precise sales data, are the main stakeholders. Recent methods using this approach are found in Refs. [182], [183] and [184]. However, as manufacturer-centric de- and remanufacturing is the central topic of this paper, less attention is given to models targeting this case.

An important lever for companies to influence the quantity and quality of return products is the application of effective return product acquisition control strategies. Indeed, the uncertainty in return volumes can be reduced by establishing a strong relation among the de- and remanufacturer and the post-use part supplier. 
Usually, in the recycling context, the degrees of freedom for applying acquisition strategies are minor while they can be very attractive for the remanufacturing scenarios, both in a productservice and in a traditional product selling business. The main goal of these strategies is to control the volume and quality of incoming products for a better matching with the market demand for remanufactured components. These strategies consist in offering to customers specific financial incentive, such as deposit, credit or cash, to encourage the returns according to related quality standards [293]. In order to capture the effect of acquisition control strategies on the resulting collection volume in a predictive way, the relationship between acquisition effort and volume needs to be forecasted and modelled [265].

\subsection{Post-use product characterisation}

Managing post-use product information is a fundamental asset since it enables de- and remanufacturing process planning and system design. Two sets of information are relevant in this context, i.e. information about the nominal product features "as designed" and information about the conditions of the post-use product. As a consequence, specific methods and tools to properly gather these pieces of information need to be adopted.

The availability of the nominal product information is becoming progressively more important as the product complexity increases. The availability of this information in de- and remanufacturing largely depends on the specific scenario. If a manufacturer-centric business is applied, this information is usually stored in the company Product Life-Cycle Management (PLM) system. In this case, in-line devices for product code reading, for example by Optical Character Recognition (OCR) and ICT solutions to extract the proper information from the company database can be adopted. However, if the manufacturer is not directly involved in the Circular Economy business or the level of digitisation of the manufacturer is low, the nominal product design information cannot be easily retrieved. In this case, different methods are adopted for gathering functional, structural and material related information. Functional and structural information are usually retrieved by reverse engineering, both concerning software and hardware. Ref. [74] proposes a reverse engineering approach for automotive mechatronics and electronics systems, as a result of the "CAN REMAN" project. The proposed five steps approach enables remanufacturing of automotive mechatronic and electronic systems, which are communicating via the CAN-bus and similar communication types. Concerning material related information, experimental analysis and knowledge-based methods are the two most widely adopted approaches. Experimental analysis consists in isolating a significant area on the component or material sample and applying quantitative or semi-quantitative material characterisation techniques, such as XRF and ICP-MS, for the analysis. Knowledge based methods instead provide estimates of the material content and concentrations in the product by inference made through the use of a knowledge base and associated rules. A knowledge base for product information supporting productcentric recycling was proposed in Ref. [234]. The methodology and related tool was applied to two products, i.e. Hard Disk Drives (HDD) and Liquid Cristal Displays (LCDs) of particular relevance for the recovery of critical raw materials. In Ref. [18] a knowledge based method for predicting the concentration of valuable materials in Printed Circuit Boards (PCBs) was developed. Starting from geometrical information about electronic components and grounding on a knowledge base and regression equations for the prediction of material contents, the material composition of the board under analysis was predicted. A promising cloud-based software infrastructure for supporting product data sharing among manufacturers and de- and remanufacturers was proposed in Ref. [290]. The platform supports the implementation of innovative, cooperative, business scenarios where the manufacturer provides or sells the access to the information to the de- and remanufacturer for improved process efficiency.
Information about post-use product conditions is relevant for developing decision support systems able to identify the best deand remanufacturing strategy, considering non-ideal parts. Two strategies have been proposed to support the development of such decision support systems, which vary depending upon the availability of in-use product monitoring data. The first strategy considers the scenario in which in-use product monitoring systems are not deployed. It grounds on the experimental assessment of the post-use product quality conditions by inspection, on grading parts by designing specific product quality classes, and on associating different de- and remanufacturing strategies to each product quality class. The main advantage is the possibility of targeting the de- and remanufacturing process to the pre-defined set of product quality classes [311]. A review of these approaches can be found in Ref. [293]. In these methods, there is an inherent complexity in defining the significant product quality characteristics to be considered and the proper inspection effort [265]. The experimental study proposed in Ref. [231] explored the trade-off between pre-process inspection effort and the cumulative remanufacturing process time. It was shown that by shifting to more thorough and time-consuming pre-process inspection plans, deeper knowledge about the product conditions can be gathered and this results in disassembly time savings. However, since inspection is time consuming, the optimal pre-process inspection plan with respect to the total remanufacturing time was defined.

Quality classification can be performed at the product supplier or collection sites, or at the remanufacturing system. Practical examples of this approach include ReCellular [88] and Caterpillar [33], where different incentives are given for different quality classes. Most of the available studies do not deal with the problem of designing the quality classes in relation to the return product technical features and failures, but concentrate on the effect of quality on the economics of remanufacturing [76,72,289]. Exception is Ref. [48] where the authors proposed a quality assessment framework for automotive mechatronic parts and derived six quality classes by experimental analysis. Based on these quality classes, different disassembly processes were planned and the required inspection technologies were assessed.

The second strategy grounds on the availability of product use data, collected by a monitoring system, and on the estimate of the Remaining, or Residual, Useful Life (RUL) of the component [133]. However, the remaining useful life of a component is not only governed by its physical life, but by its technological life as well. As a result, both these factors should be taken into consideration before a de- and remanufacturing decision is made. The first step in estimating the RUL is the assessment of physical lifetime, $T_{B}$ which is the difference between the operating life, $T_{O}$, and the usage life, $T_{U}$, of the component. The value of $T_{O}$ can be estimated by using various methodologies, with Weibull analysis being one of the most common, whereas the estimation of $T_{U}$ requires collection of lifetime prediction parameters during the usage life of the product. Once the relevant usage data is collected, various techniques such as statistical techniques, regression analysis, Kriging techniques, vibration analysis or Artificial Neural Networks (ANN), can be used [138,134,186]. The second step of the approach is the assessment of the technology life, $T_{t}$. Growth curves, or S-curves, are commonly used in forecasting the adoption of new technology and hence the obsolescence of its predecessors. Finally, the remaining useful life, $T_{R}$, can be estimated as the minimum of these values. The $T_{R}$ value can be used to determine a suitable de- and remanufacturing strategy [139]. For instance, in order to determine the reuse potential of post-use components, their remaining life, $T_{R}$, should be at least greater than the average product service life, $T_{A V}$, that is, $T_{R} \geq T_{A V}$.

Since managing product information is a strategic asset for deand remanufacturing decision making, advanced software platforms for supporting automatic use-phase product data collection, storage and analysis are important developments for supporting industrial implementations. For example, within the Premanus project, an on demand middleware with service-oriented archi- 
tecture was developed [65]. Within this platform, product use data collected by sensor networks, product design information as well as manufacturer information about product end-of-life routes are made available on-demand to connected users.

\subsection{Process-chain planning}

The area of process planning for de- and remanufacturing systems was extensively addressed in the last decades. However, different branches of literature treat the process planning problem at different stages of the de- and remanufacturing process-chain. As a consequence, isolated approaches for disassembly, remanufacturing and recycling process planning have been proposed. Therefore, the major contributions are revised following the same point of view. In general, de- and remanufacturing process-chain design takes in input the post-use product characterisation and is dedicated to the problem of selecting the processes and their parameters, the related technologies and the process workflow.

The area of disassembly process planning originated as a byproduct of the assembly planning theory and was originally proposed by Bourjaul [161]. The problem of finding the optimal disassembly level and sequence for a post-use product that maximizes the overall profit, requires integer linear programming methods that easily become inefficient in terms of CPU time when applied to complex products. Therefore, researchers have opted to rely on heuristic and metaheuristic methods in order to achieve "good enough" solutions; however, often the quality of such solutions is not guaranteed, making exact methods essential tools to benchmark the obtained solutions [163]. One of the first applications of exact methods for solving the sequencing problem, utilizing disassembly precedence graphs and a network flow approach, was presented in Ref. [291]. In Ref. [130] the authors extended this method utilizing modified AND/OR graphs, called extended process graphs, and integer programming. In Refs. [161] and [162] adapted versions of this method, that relax the integer linear problem into a binary integer linear programming problem, solved through an iterative procedure, were proposed.

Metaheuristic and heuristic methods for optimal disassembly sequencing have been used by researchers for a considerable amount of time. An early example is reported in Ref. [89] that proposed a heuristic algorithm for sequence dependent cost employing a disassembly precedence graph applied for computers remanufacturing. Metaheuristics which have been broadly used include genetic algorithms [107,152,57,83], particle swarm optimisation [291,307] and the greedy randomised adaptive search procedure $[1,2,6]$.

However, the full disassembly of a product tends to be unproductive due to technical and cost constraints and product conditions after usage [239]. Although "selective disassembly" is a more practical approach, where only a limited number of disassembly paths that lead to selected parts with recovering potential are considered, there is very little research being carried out in this area. Methods for selective disassembly sequencing based on a well-known assembly sequencing approach is proposed in Refs. [166], [135], and [136]. The applicability of the methodology was demonstrated by using a washing machine case. The major advantage of the reported methodology is to provide a graphical representation of disassembly sequences at different stages of the process, which allows the user to visualize the disassembly process.

Within disassembly process planning, the disassembly to order system has been also studied [153] by using integer goalprogramming. Here the objective is to determine the best combination of multiple products to selectively disassemble to meet the demand for items and materials under different constrains and goals, e.g. financial and ecological.

In the area of recycling process planning the objective is to determine the material distribution in the output streams of a recycling process-chain starting from a known input material composition, with the goal of finding the right process plan to satisfy required recovery and grade targets for specific valuable materials. The available methods for planning recycling processes can be grouped in two categories [303], i.e. (i) recycling process models, estimating the process performance as a function of the process parameters via physics-based models, and (ii) material flow models, analysing the integration of multiple size-reduction and separation processes in a process-chain.

Among the first group of contributions, models have been developed for size-reduction, separation and end-refining processes. For size-reduction processes, the most widely adopted models are in the class of Population Balance Models (PBM) [28]. In these models, the evolution of the mass belonging to specific product material classes during the dynamics of the size reduction process is analysed by a stochastic process, whose evolution is driven by estimated material selection, breakage and discharge functions. For separation processes, physics based models have been proposed. The force field originated by the separation technology is modelled and its effect on the trajectories of the particles under processing is quantified [179]. Most of the models, however, are deterministic in the sense that they consider single particle flows and neglect the effect of particle-particle and particle-equipment interactions on the variability of the separation process performance. To overcome these limitations, granular flow multi-body simulation models have been recently developed [47]. Due to the millions of impacts generated during the process, the traditional Discrete Element Method (DEM) approach is replaced by an innovative Differential Variational Inequalities (DVI) formulation, which considerably reduces computational times. These models, once validated against experimental results, can also be used to optimise the process parameters for target recycling performance [30].

Among the second group of contributions, one of the first models for recycling process-chain planning was the one described by Sodhi et al. who present a method based on dynamic programming to determine the best sequence for material recovery [249]. Ignatenko et al. proposed the combined use of transformation matrices to model the effect of processes on the material flow routings and linear mass-balance equations to capture the effect of each process stage at process-chain level [110]. In absence of realistic process models, the parameters of these matrices have to be estimated by experimental analysis. The authors also emphasised the need for a comprehensive particle modelling framework in order to link product design, material liberation and the recycling system performance [32,283]. This approach better supports the implementation of the productcentric recycling concept, proposed to overcome the limits of the traditional material-centric approach.

Gutowski et al. presented a probabilistic material separation model based on the Bayes theorem to estimate the performance of binary separation processes [91]. This approach was extended to multi-stage separation processes, by means of a network model [303]. This model can be employed to support the efficient planning of recycling process-chains and was used to evaluate recycling treatments for plastic separation and for end-of-life processing of LCD TVs [284]. In Ref. [43] partition curves are used to describe the separation efficiency of a particular process setup and include the effect of material entanglement. Specific software packages are available for supporting recycling process planning $[230,281,226]$. For example, one of the most recent tools is proposed in Ref. [281], based on size-reduction, separation and end-refining processes models. The software package supports the planner in the construction of the process-chain and optimisation of the process parameters. It is also linked to environmental evaluation based on Life-Cycle Assessment (LCA).

Remanufacturing process planning is an area of research that has been recently systematised focusing on selecting the operations, sequences, and tools to regenerate the used products with high remanufacturing quality [309]. In Ref. [208] a systematic approach for the planning and execution of product remanufacturing based upon the failure mode and effect analysis method was developed. In Ref. [141] a Mixed Integer Programming (MIP) 
approach to optimise remanufacturing process plan in terms of cleaning, injecting, disassembly, repairing and reassembly is presented. The reconditioning process planning, however, is still performed by the user who inputs the process in the software through a graphical user interface (GUI). Ref. [167] considered the uncertainty in the quality of incoming used components and adopted a Graphical Evaluation and Review Technique method for remanufacturing process plan decisions. Ref. [168] established remanufacturing process model based on a fuzzy Petri net in view of the uncertainties in remanufacturing process routing and process times. Ref. [145] presented a seven-step procedure for remanufacturing process planning including (i) identify defects and their locations, (ii) assess and rank defect criticality, (iii) identify reconditioning operations for each defect, (iv) identify precedence relationships, (v) revise reconditioning process sequence, (vi) perform risk and reliability assessment, (vii) suggest a preliminary selection. In addition to the product quality, the cost in remanufacturing is another criterion that should be taken into consideration for process planning. In Ref. [124] the authors proposed a remanufacturing multi-objective process optimisation method to maximise the reliability and minimise process cost, based on Genetic Algorithms. Multi-criteria decision making problem formulation was also adopted in Ref. [123] for performing technology selection by Analytic Hierarchy Process (AHP). Environmental and economic factors were considered.

Although the literature provides several methods and tools to perform de- and remanufacturing process planning, there is a lack of approaches for integrating strategic decisions on Circular Economy options with consideration of process capabilities. This would be a useful tool for supporting process planning in manufacturer-centric Circular Economy contexts.

\subsection{Feed-forward process control by Cyber-Physical Systems (CPSs)}

With the objective to adapt the de- and remanufacturing process to evolving features of the product under treatment or to quickly changing market demand requirements, system control plays a fundamental role. In particular, since most of the variability and uncertainty in de- and remanufacturing systems is due to the condition of input products, feed-forward process control solutions result to be particularly attractive. In feed-forward control the control variable adjustment is not error-based. Instead it is based on knowledge about the process in the form of a mathematical model of the process and knowledge about, or measurements, of the process disturbances. The implementation of feed-forward control solutions in industrial systems requires the design and development of innovative control architectures. Recently, distributed and scalable control solutions based on IEC61499 and Cyber-Physical Systems (CPS) have been proposed in the manufacturing area as suitable technologies for supporting rapid reconfiguration and system evolution at shop floor level [193]. CPSs are large-scale interconnected systems of heterogeneous components that are envisioned to provide integration of computation with physical processes. CPSs can provide broad controls over complex and large industrial processes through a heterogeneous network architecture of sensors, actuators and processors. Computational processes, which constitute the cyber part of the system, accept inputs from the physical processes, calculate the outputs required to affect the physical processes and apply these outputs to the physical plant. Recently, CPS solutions for de- and remanufacturing systems have been developed. An example of a prototype CPS solution for recycling is reported in Fig. 13 [220].

The CPS gathers in-line data about the processed mixture composition by using a HyperSpectral Imaging (HSI) system and adjusts the parameters of the downstream electrostatic separation process according to the specific mixture under treatment. The preliminary experimental results, obtained by processing shredded WEEE cables and PCB mixtures, show that a considerable improvement in the recovery can be achieved.

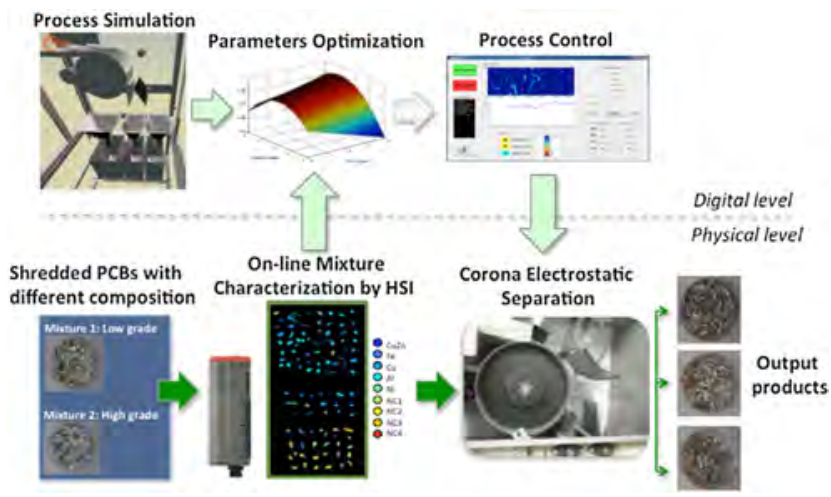

Fig. 13. CPSs for demanufacturing process control [220].

Cyber-Physical Systems have also been developed to adapt remanufacturing processes based on the information about product damages gathered by automatic, vision based, data acquisition systems, in feed-forward mode [252]. In Ref. [195] a reverse engineering approach is used to obtain a digital model of the part and adapt the parameters of the subsequent laser remanufacturing process, on high-value mechanical parts. By directly generating the machining path from the cloud of points obtained by inspection, the cycle time can be reduced for meeting industrial implementation requirements. A similar application to the case of large-scale turbine blades is reported in Ref. [78].

\subsection{De- and remanufacturing production planning and control}

Production planning and control in de- and remanufacturing addresses problems of capacity planning, production planning, scheduling and inventory management. The specific challenges of these problems in de- and remanufacturing are due to (i) fluctuations in the quantity, quality, and lifespan of products for reuse or material recovery, (ii) mismatch between supply and demand, and (iii) the limited capability of substituting regenerated parts into the product [151]. Most of the models developed address independently disassembly for remanufacturing or dismantling for recycling decisions.

In the area of dismantling for recycling decisions, only few contributions are available mainly dealing with the capacity planning problem, especially in the automotive end-of-life treatment scenario. This is due to the difficulty to control the product acquisition process and to the wide adoption of make-tostock productions. In Ref. [171] an optimisation model for recycling systems capacity planning for end-of-life vehicles in view of profit maximisation was proposed. The authors included operating capacity, inventory capacity and costs in the proposed MIP model. They extended the model to consider the effect of different hulk acquisition pricing policies and uncertainty in returns [225]. In Ref. [247] the authors proposed a similar model and explored the effect of legislation targets on the planned facility performance.

A wide body of literature has studied production planning and control in the area of disassembly for remanufacturing decisions. Reviews can be found in Refs. [129], [112], [160], [192] and [185]. Both hybrid manufacturing-remanufacturing systems and non-hybrid remanufacturing systems have been analysed. However, the first area is more relevant from a manufacturer-centric Circular Economy perspective. The goal of these studies is to decide how to coordinate manufacturing and remanufacturing operations considering uncertainty in product returns and demand. In Ref. [221] the authors studied by a continuous time stochastic control approach a production control problem for an hybrid manufacturing-remanufacturing system considering stochastic returns, demand and the presence of set-up times while switching from assembly to reassembly modes. In Ref. [52] a multi-period remanufacturing planning with uncertain input quality was analysed by stochastic programming, considering binary quality levels with pre-defined probabilities associated. This model 


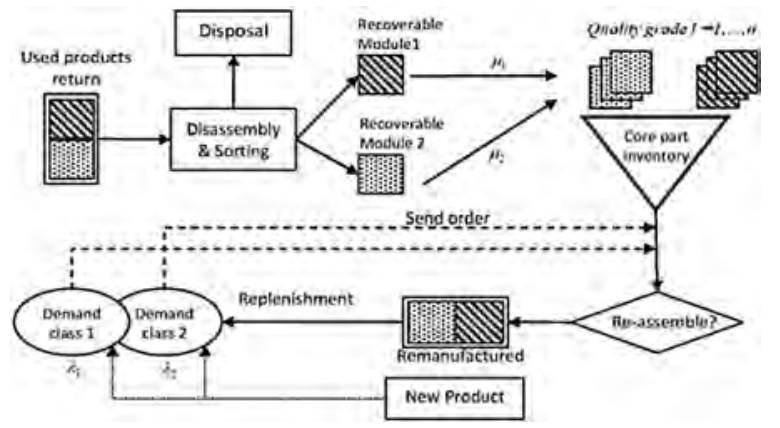

Fig. 14. Reassembly to order in remanufacturing [125].

considered the variant quality levels at the single product level, however, ignored the module-level quality variation. In Ref. [125] the problem of reassembly planning and inventory control of a multi-module product with supply and demand uncertainties is considered. The authors considered a reassemble-to-order setting in the remanufacturing environment, as shown in Fig. 14. The authors solved the problem by using a Markov decision process formulation and derived a state-dependent threshold based policy for production control. In Ref. [8] production and inventory planning simulation models are proposed to virtually test various lot sizing policies before implementation.

The supply and demand balance is the most critical factor also in the scenario of product reuse by function reconfiguration and upgrade. To implement reuse, one needs to match the original use with the subsequent reuse in terms of volume and quality. However, on the demand side, the requirements for the reused items vary depending on individual subsequent users. On the supply side, product return is at the users' discretion once the products have been sold. In this case, product providers do not have any control over the volume and quality of the returned products. To solve this problem, planned, or forced, circulation has been proposed. In this case, products are owned by the provider. This concept was applied to the reuse of copier photoconductor drum units [262] and a group of copiers used in an office [261]. Another strategy to mitigate the difficulty in matching the demanded performance with that of the returned items is to increase the variety of supplies of the reused items. For this purpose, the concept of module reconfiguration remanufacturing has been proposed, where the modules extracted from the returned products of different product generations are reconfigured to satisfy various user requirements [280,238]. An imbalance in volume may occur because of a time lag between a period of the peak demand for reuse products and that of the peak for product returns. Therefore, appropriate sales periods must be selected to control deficiencies or excesses of returned products [237].

One of the few works considering planning in an integrated disassembly, remanufacturing and recycling environment is proposed in Ref. [151]. The authors developed a simulation model considering material and component characteristics, inspection, remanufacturing and recycling process characteristics as well as different network configurations in order to validate control policies on the basis of the implications with material flow issues.

\section{De- and remanufacturing system design}

In this section, the main problems, methodologies and tools for supporting the design of smart de- and remanufacturing systems are revised. A de- and remanufacturing system embeds the set of processes, human and technological resources, organisation, and ICT infrastructure to enable effective product de- and remanufacturing [46]. These issues are discussed in the following.

\subsection{Business models for de- and remanufacturing}

In order to be economically sustainable and risk robust, manufacturer-centric de- and remanufacturing ventures require specific business models that differ from those typically adopted in manufacturing. From the demand side, new customer segments, interested in lower purchasing prices for steady product quality, need to be exploited [292]. From the post-use part supply side, the customer behaviour strongly influences the quality of post-use products, which in turn increases the degree of complexity in the planning and execution of de- and remanufacturing processes [297]. Keeping product ownership on the manufacturer side is a strategy to overcome such challenges, by changing the role of deand remanufacturing activities as "a service in the product's lifecycle" [202]. The concept of Product-Service-System (PSS)-based business models, grounding on the idea of selling functionality rather than the product itself [85], are very promising in de- and remanufacturing, in particular in the scenario of product remanufacturing for upgrade [216]. The value proposition consists in designing products for prolonged use cycles and motivates service providers to collect and value post-use products as a direct strategy to increase economic benefits. As customers are solely interested in reliable product functionalities for an agreed price, they do not perceive used products as problematic as long as use availability is ensured.

This value proposition shall be accompanied by enabling solutions for effectively implementing the service. In-use product monitoring systems can support manufacturers in deciding the time when a product upgrade should be offered to the customer, also gaining useful field knowledge for product re-design. For those products that cannot be efficiently monitored, Östlin et al. suggest to link customer relation to core procurement. Compensation for old products in form of a discount for a new product or monetary compensation incentivise customer to return used products in the best possible condition [203]. This idea is supported by multi-sided virtual platforms, which facilitate interactions between user and provider by managing and recording their communication history, while providing delivery or payment services [201]. Among these, CoremanNet is a platform where remanufacturers can procure cores while customers dispose their used products as a condition to obtain remanufactured products at a preferential rate.

\subsection{De- and remanufacturing system engineering}

The engineering of de- and remanufacturing systems is strongly influenced by the specific business model. The main activities in this area consist in the definition of the system architecture and coevolution level, the assignment of tasks to workstations, the design of the technological contents and the automation level of workstations, and the design of buffers for meeting desired production rates and quality levels, in coherence with the defined manufacturing strategy and business model [268]. Also in this area, the different phases of the de- and remanufacturing process-chain are usually designed in isolation.

While the disassembly planning problem has been extensively studied in the literature, the design of disassembly systems has attracted less interest. A large scope of the scientific literature is devoted to the decision problems related to the design and operation of assembly systems [103]. Unfortunately, these results cannot be directly transferred to disassembly as it cannot be simply assimilated to the reverse of the assembly process [295]. However, the experience gained in the field of assembly may provide useful guidelines for disassembly system design.

In spite of the uncertainty and variability of return product conditions, most of the methods for disassembly systems design deal with deterministic input data. In terms of system architectures, serial, U-shaped and parallel station disassembly systems have been considered [296]. The Disassembly Line Balancing Problem (DLBP) was originally introduced in Ref. [90]. It consists in the assignment of disassembly tasks to workstations of a disassembly line with the objective to optimise measures of effectiveness, usually economic. To deal with the deterministic DLBP, heuristic, metaheuristic approaches and mathematical programming formulations were developed [17,132,148]. Recent 
works studied the design of disassembly lines under uncertainty, where task failures, post-use product conditions, component demands, and task times were considered as sources of uncertainty. In Ref. [9] a MIP for maximizing the profit generated by a disassembly line considering the possibility of the reassignment of the remaining tasks if one disassembly task fails was provided. In Ref. [271] the authors used a Monte Carlo based reinforcement learning technique to solve the multi-objective DLBP under demand variations of the retrieved parts. Disassembly task time uncertainty is usually modelled by independent random variables with known normal probability distributions and is introduced to capture manual disassembly tasks or disassembly tasks under variable conditions of the product. For example, a collaborative ant colony algorithm for stochastic mixed-model U-shaped DLBP was developed by Ref. [3]. In Ref. [23] the authors studied the cost-oriented DLBP with complete disassembly process. The uncertainty of line stoppage caused by stochastic task processing times was modelled using the notion of recourse cost. A two-stage stochastic linear MIP with fixed recourse was adopted. In Refs. [25], [24], and [26], selective disassembly was considered and the uncertainty was modelled using workstation expectation times instead of direct station times. A joint precedence graph was used to consider the uncertainty of the return product conditions in Ref. [232]. A disassembly line balancing approach taking into account the uncertainty of post-use products quality and task times was proposed and tested on a case study in Ref. [48].

The problem of evaluating the performance and designing buffered disassembly lines has also attracted interest in the research community. Here the objective is to allocate buffers to smooth the propagation of flow interruptions along the line generated by variability of processing times and stochastic machine failures. Analytic based methods for buffer allocation and workload design in assembly/disassembly networks were proposed in Refs. [194] and [44]. These methods consider workstation failures and deterministic processing times in the analysis. These methods usually assume fixed product routings.

The definition and the design of the level of automation in disassembly systems has been a topic of research since the $90 \mathrm{~s}$ [127,296,22], although applications of automated solutions in industry are still fairly limited [242]. According to Ref. [288] the automatic disassembly system can be considered a robotic system that employs an artificial intelligence agent controlling the mechanical operation units and sensors. The system achieves flexibility [267] and reconfigurability [155] by perceiving relevant information during the process and adapting the operation accordingly [287]. As a consequence, system design methods cannot be based on the assumption of predefined routings, as in the case of manual disassembly, but re-routing of parts has to be considered as an integral part of the system design process. Moreover, specific data acquisition systems on the product to be disassembled, image processing systems, data storage and management systems and control systems need to be integrated [143]. In Ref. [58] a methodology to support the design of reconfigurable automated disassembly systems for multiple product types has been proposed. In Ref. [299] a systematic analysis of automated and semi-automated flexible disassembly layouts is provided and a classification of the basic modular components, including tools, fixtures, robots and sensors, is given for enabling changeability of the system [298]. Methods for designing cognitive robotics, covering sequence planning, image acquisition, process adaptation and interaction with the human operators are revised in Ref. [288]. In Ref. [61] an online genetic algorithm model for selective disassembly in a robotic disassembly cell for electronic products is proposed for optimal and nearoptimal disassembly sequencing. In Ref. [189] an ontology-based framework for supporting automated disassembly was proposed where gathered field data and nominal product data are coherently stored in order to support disassembly operations. In Ref. [240], an information system architecture for flexible automated disassembly is presented. Furthermore, capability for adaptation of the robot motion when new conditions are observed have to be provided to the system, especially in a cooperative HRC environment. In Ref. [214], an off-line approach generating the robot trajectories on the basis of a probabilistic definition of the human movements is combined to an on-line method to adapt the robot speed in order to avoid collisions between the robot and the human when the environment is not fully controllable.

In recycling, most of the contributions focus on recycling process-chain planning, while only few works consider the system engineering problem. Ref. [45] proposed a multi-level recycling system model to support the joint configuration of the system layout and process parameters. The authors showed that in recycling systems an interesting trade-off between quality of the separation and throughput exists, in the sense that increasing the material flow rate, increases the impacts among particles in the mixture and this, in turn, increases randomness and decreases the separation quality. This work emphasised the need for reconfigurable and adaptable recycling systems for better responding to market and input product evolutions. In Ref. [21], the same paradigm of reconfigurable recycling systems was formulated, with an example of a robotic cell for control units processing. In Ref. [258], principles of lean manufacturing are used for the improvement of the performance of a recycling plant in Sweden by adopting layout planning and bottleneck analysis. The use of an Interactive Genetic Algorithm (IGA) method for designing the facility layout of recycling plants taking into consideration subjective features from the designer and technological constraints is proposed in Ref. [81]. The method is applied to two reallife recycling plants. Applications of recycling systems design methods in specific areas are proposed in Ref. [41] concerning the case of a photovoltaics recycling infrastructure, and in Ref. [227] for designing a system for carpet recycling. Recent contributions also addressed the design of innovative recycling systems supporting new business models. For example in Ref. [233] the design of a modular end-refining system implementing hydrometallurgical processes in transportable containers is discussed. Such design can support innovative business models of migrating recycling cells for high utilisation at different locations.

In remanufacturing, system engineering has been applied mainly for selecting and allocating resources, namely buffers and processing stations, in order to meet target productivity performance [4]. Usually, performance evaluation methods common of discrete part manufacturing are adopted, among which discrete event simulation and analytical methods. In Ref. [31] the concept of adopting a cellular U-shaped layout design for remanufacturing systems in order to better cope with internal and part variability and reduce the material flow costs is proposed and specific design guidelines based on the lean manufacturing principles are provided. In Ref. [79] an ant colony based optimisation method to optimise cell layout design for reducing the material handling cost at the used product post-disassembly stage is proposed, in a job shop remanufacturing cell. In Ref. [73] an integrated capacity planning and factory adaptation model was proposed for designing and reconfiguring automated mobile phone disassembly and remanufacturing cells, based on mathematic programming and discrete event simulation. In Ref. [5], a remanufacturing system consisting of disassembly, testing and remanufacturing modules is considered. A methodology based on open queuing networks for obtaining a near optimal buffer allocation solution in cellular remanufacturing systems was proposed. At high abstraction levels, conceptual models and frameworks for a preliminary design of remanufacturing facilities are proposed in Refs. [131] and [117]. These high level models are useful for an early stage conceptualisation of the system and for supporting strategic investment evaluation based on technical considerations on the system capabilities.

\subsection{Reverse logistics network configuration}

The design of Reverse Supply Chains (RSC), or reverse logistics network, is a complex strategic problem where numerous 
economic, legislative and logistic factors have to be analysed. The objective is to set up a number of facilities mandatory for the reverse logistics, such as collection centres, disassembly and recovery facilities, to determine their capacities and to organise the flows between them, looking for the total network efficiency. The design of reverse supply chains usually takes into account the EPR and the incentives offered by firms to consumers or by the government to the firms $[13,204]$. The common models used for forward supply chains have to be adapted to RSC due to high level of uncertainty related to product returns, more complex network structure, wider variety of sources, more complex functions in terms of cost, services and environmental impacts, and unexplored market opportunities [94]. In the literature, the common tools for modelling these uncertainties are stochastic programming $[250,122]$, fuzzy programming $[126,255]$ and simulation [137]. See Refs. [84] and [119] for recent reviews.

A reverse logistics network supports manufacturers in the identification and collection of post-use parts. There are various adopted collection strategies such as drop-off, periodic kerb-side, mail-in, point of sales [95]. Planning collection networks needs to take into account location, product type, population density, transportation and cost and environmental impact of chosen collection strategies [96]. Furthermore, there are multiple independent stakeholders such as end-user, councils, retailers, OEMs, waste management centres and recyclers. Therefore, it is imperative that all these stakeholders collaborate in any collection network design in order to reduce cost and environmental footprint and increase collection efficiency [96]. Ref. [62] dealt with collection and recycling centres while scoring the products in terms of recyclability, biodegradability, energy consumption and product risk. Ref. [92] addressed the integrated management of collection-disassembly in reverse chains.

Another branch of research concerns the simultaneous design of forward and reverse parts of the closed-loop supply chain (CLSC) (Fig. 15). Ref. [71] considered the CLSC with complete reprocessing of an end-of-life product, the reuse of components, the disposal of unusable parts sent directly from the manufacturers, with a closed loop transportation system that maximizes transportation efficiency. Ref. [191] considered a multi-period, multi-product, multiechelon and capacitated supply chain design problem for short lifetime products. The network design included suppliers, hybrid production-inspection centres, hybrid warehouse-collection centres, retailers, disposal centres and recovery centres. Ref. [306] analysed the effect of carbon emissions consideration on the design of both hybrid and dedicated CLSCs. Numerous case studies have shown the design of CLSC in various industrial contexts among which lead/acid battery [255], construction machinery remanufacturing [308], electrical and electronic equipment [10], and solar energy industry [36].

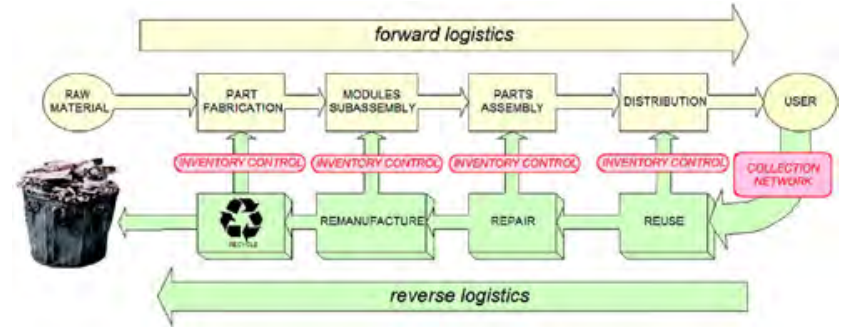

Fig. 15. Forward and reverse logistics activities [137].

\section{Socio-economic aspects of de- and remanufacturing}

\subsection{Industrial symbiosis and value chain integration}

Industrial symbiosis, which is seen as a sub-field of Industrial Ecology, is an efficient cross-sectorial strategy to implement Circular Economy businesses. The concept is based on the works of Frosch and Gallopoulos who stated that "waste from one industrial process can serve as the raw materials for another, thereby reducing the impact of industry on the environment" [75]. The authors established the basis for the United Nation's idea of using geographic proximity and regional eco-systems as a way of linking separate industries in their exchange of physical goods like water, material, energy and by-products [37]. The Kalundborg Symbiosis in Denmark is one of the most prominent examples in which the principles of Industrial Symbiosis are applied. The estimated savings reach US $\$ 10$ million a year. Other practical examples are revised in Ref. [55].

Value chain integration is another strategic opportunity to boost Circular Economy businesses. It entails collaboration between businesses at the level of planning and information sharing among different stakeholders in the value chain. As highlighted by the industrial cases reported in Section 1, by creating stable partnerships among stakeholders a better alignment and higher efficiency of de- and remanufacturing operations can be achieved [297]. In this context, multilateral information systems for life-cycle management appear as useful tools [277] to follow the whole product life-cycle from supplier to end-user, ultimately adding value and gaining maximum utilisation of resources [295]. The collaborative research project BRAGECRIM focuses on the effectiveness of value-chain integration in remanufacturing [86]. It proposes a classification into three types of value-chains including (i) networks where the manufacturers carry out remanufacturing processes themselves, (ii) networks where subcontractors are the main actors of remanufacturing, and (iii) networks of independent remanufacturers, i.e. without contractual agreement with the original manufacturer [87]. In each value-chain, specific sub-sets of problems are relevant. For example, core procurement is challenging for type (i) while remanufacturing processes are more critical for type (iii).

\subsection{Legislation and cultural boundaries}

Legislation and cultural aspects, and the related uncertainties, constitute additional boundaries on the implementation of innovative manufacturer-driven Circular Economy businesses and need to be considered in order to achieve business profitability. The European Remanufacturing Network [70] identifies legislative and trade barriers and lack of standards as major problems for expanding remanufactured products markets. So far, European legislation regulates recycling with a sectors-oriented approach. In automotive, the directive on end-of-life-vehicles (2000/53/EC) and the directive on reusability, recyclability and recoverability of waste vehicles (2005/64/EC) set standards for the quality of reused parts and materials. In electronics, the RoHS directives on hazardous substances in electrical and electronic equipment (2002/95/EC and 2011/65/EU) and the Waste Electrical and Electronic Equipment (2002/96/EC) address the issue of product design and post-use treatment. As a matter of fact, remanufacturing remains legally undefined in most countries, although efforts have recently being invested on the "end-ofwaste" regulation. In South Korea, the government and remanufacturers of automotive parts have enacted a norm for remanufacturing process definition [86]. In Europe, specific actions have been launched for identifying potential legislative barriers for the development of new Circular Economy businesses through the "Innovation Deals" initiative [68]. Moreover, the SCREEN project has been launched to involve Regions in the identification of Circular Economy areas of innovation and potential legislative barriers to their implementation [67]. Another significant challenge in remanufacturing concerns Intellectual Property (IP). In Ref. [97] it is reported that a lack of understanding of how to manage the uncertainties associated with IP in remanufacturing represents a significant challenge for industry wishing to adopt a remanufacturing approach. In this context, a manufacturer-centric de- and remanufacturing approach can benefit from a better protection of confidential product information. Cultural boundaries also play a relevant role in the achievement of profitable 
circular businesses, since they affect post-use product collection, the market acceptance of reconditioned products and the effective transition towards use-oriented businesses. Ueda et al. [273] outline an axiology of value creation for sustainable manufacturing. They suggest de- and remanufacturers to devote more attention to social mechanisms of value creation, such as network externality, social dilemma, public goods, and lifestyles aspects into their value proposition.

\subsection{Social aspects in de- and remanufacturing}

Modern Circular Economy businesses supported by smart deand remanufacturing systems have several beneficial social implications. From a global social perspective, Circular Economy may smooth the coupling of specific critical resources with conflict areas where environmental, humanitarian and global security problems persist because of the market demand for such resources, as for example for tantalum in Africa, thus contributing to a fairer and more balanced market of critical raw materials. From a consumer perspective, de- and remanufacturing supports the concept of "Frugal Innovation" since it enables manufacturers to offer affordable high-quality products in the emerging global markets [165]. Example of a profitable business in this direction is the remanufacturing of diagnostics medical machines at Philips Healthcare [70]. This high-value equipment is regenerated, customised for regional market requirements, and sold in emerging markets. This would open new business opportunities, increasing the competitiveness of companies in high-wage countries, at the same time increasing customer satisfaction in emerging economies [104]. From a job creation perspective, de- and remanufacturing makes it possible to create high quality and highskill jobs, both in low wage and high wage countries [29,38]. Indeed, the highly variable conditions in de- and remanufacturing create a problem-solving oriented environment that stimulates workers creativity and boosts personal motivation and reward. Safety is a critical aspect of de- and remanufacturing processes, due to the potential risks of interaction with hazardous substances for both employees and local residents [222]. Safety requirements put a premium on smart de- and remanufacturing systems, were high level of monitoring and control is implemented.

\section{Future research priorities}

In this section, based on the framework proposed in Section 2 and the contributions revised in Sections 3-5, relevant gaps are identified which constitute future research priorities.

\subsection{Circular Economy engineering}

Different Circular Economy practices are usually investigated in isolation. However, within the same post-use product, different components may be suitably recovered by a mix of Circular Economy strategies, due to their features, functions and materials. A new Circular Economy engineering theory shall be developed, able to combine strategies to recover the highest residual value from post-use products, considering the existing options in a holistic way.

\subsection{Design of circular factories}

Under the proposed manufacturer-centric Circular Economy perspective, circular factories should be designed considering the requirements deriving from product manufacturing as well as post-use product de- and remanufacturing, after the use-phase related time delay. In this perspective, a new set of manufacturing system engineering methods for the design of circular factories shall be developed, capturing different sources of uncertainty in a multi-period problem and exploiting the synergies among the processes and technologies adopted in multiple product cycles.

\subsection{Zero-defect de- and remanufacturing}

The quality of recovered materials and remanufactured products affects the profitability of Circular Economy businesses. Differently from manufacturing operations, in de- and remanufacturing significant product variations are observed in the input flow of post-use products. To support effective regeneration, a new systemic zero defect solution should be developed, able to gather in-line data by distributed inspections and elaborate them to smooth the propagation of part variations throughout the process stages, by adjusting process parameters depending of the specific features of the part or material under treatment.

\subsection{Automation level in de- and remanufacturing systems}

The use of automated solutions in de- and remanufacturing systems has been investigated, but their systematic implementation in industrial practices is still controversial. In favour of this transition, de- and remanufacturing design and management methods should be adapted to consider fully automated and hybrid operations as suitable options, where technologically feasible. This would support designers to determine the optimal automation level depending on product and context related variables.

\subsection{Adaptable de- and remanufacturing systems}

Due to the high level of uncertainty in post-use product conditions and demand, adaptable de- and remanufacturing processes and systems would contribute to increase regeneration rates, by reducing operational and investment costs. New technical enablers for adaptability should be developed, such as modular transportation and smart material routing systems, reconfigurable control solutions, flexible robotic sorting systems, and multisensor data gathering systems for product and material inspections. These solutions, combined with new co-evolution design methods, would contribute to the development of low capacity systems, able to quickly adapt to evolving products and market conditions.

\subsection{Digital factory technologies}

In spite of the availability of tools to support de- and remanufacturing planning, there is a lack of digital platforms to support the integrated design of de- and remanufacturing processes and systems. At process level, simulation capabilities shall be incorporated, to support process parameters setting. At system level, such tools should provide a "digital twin" of the real plant and support tactical and operational decision making in highly uncertain environments.

\subsection{Legislation aware de- and remanufacturing design and planning}

Legislation and cultural conditions have an impact on de- and remanufacturing system strategic and operational decisions. For example, Ref. [213] shows how legislative conditions affect the workflow of LCD treatment plants in Japan and Europe. Therefore, methods to embed such boundaries conditions in the de- and remanufacturing design problem should be developed.

\subsection{New circular business models and value-chains}

Profitable opportunities for closing the loop can be originated by establishing new cross value chain businesses. However, a systematic methodology to identify such opportunities and links is missing and this results into truncated material cycles and loss of business opportunities. A material-product flow oriented systemic approach would suitably support industry and public authorities in the identification of these untapped potentials. 


\section{Conclusions}

This paper has formalised a new manufacturer-centric Circular Economy model and the related requirements towards the next generation of smart de- and remanufacturing systems. The most advanced emerging technologies and methods have been revised and promising directions for future research have been highlighted. As emerges from the analysis, most of the highlighted challenges and requirements find proper solutions in the scientific literature, although higher Technology Readiness Level (TRL) shall be achieved in order to reach application in industrial settings. In this direction, substantial efforts should be devoted to integrating and demonstrating existing solutions at pre-industrial scale, in order to support companies in the transition towards a disruptive business change. To this aim, the creation of collaborative valuechains and local eco-systems may strongly contribute in boosting new Circular Economy businesses and the related social impacts.

\section{Acknowledgements}

The authors would like to thank Eng. Marco Diani, Politecnico di Milano, Dr. Nicoletta Picone and Dr. Stefania Pellegrinelli, ITIACNR, Dr. Thomas Guidat, TU Berlin, and Eng. Nicolas Paquet, Indra, for the support in the preparation of this paper.

\section{References}

[1] Adenso-Díaz B, García-Carbajal S, Gupta SM (2008) A Path-relinking Approach for a Bi-criteria Disassembly Sequencing Problem. Telecommunication Network Engineering 35(12):3989-3997.

[2] Adenso-Díaz B, García-Carbajal S, Lozano S (2007) An Efficient GRASP Algorithm for Disassembly Sequence Planning. OR Spectrum 29(3):535-549.

[3] Agrawal S, Tiwari M-K (2008) A Collaborative Ant Colony Algorithm to Stochastic Mixed-model U-shaped Disassembly Line Balancing and Sequencing Problem. International Journal of Production Research 46(6):1405-1429.

[4] Aksoy H-K, Gupta S-M (2005) Buffer Allocation Plan for a Remanufacturing Cell. Computers and Industrial Engineering 48:657-677.

[5] Aksoy H-K, Gupta S-M (2010) Near Optimal Buffer Allocation in Remanufacturing Systems With N-policy. Computers and Industrial Engineering 59(4):496508 .

[6] Andrés C, Lozano S, Adenso-Díaz B (2007) Disassembly Sequence Planning in a Disassembly Cell Context. 16th Int Conf Flex Autom Intell Manuf 23(6):690-695.

[7] Andrew-Munot M, Ibrahim R-N (2013) Remanufacturing Process and Its Challenges. Journal of Mechanical Engineering and Sciences 4:488-495.

[8] Andrew-Munot M, Ibrahim R-N (2013) Development and Analysis of Mathematical and Simulation Models of Decision-making Tools for Remanufacturing. Production Planning and Control 24(12):1081-1100.

[9] Altekin F-T, Akkan C (2012) Task-failure-driven Rebalancing of Disassembly Lines. International Journal of Production Research 50(18):4955-4976.

[10] Amin S-H, Baki F (2017) A Facility Location Model for Global Closed-loop Supply Chain Network Design. Applied Mathematical Modelling 41:316-330.

[11] Apra - Automotive Part Remanufacturers Association (2012) Remanufacturing Terminology, Remanufacturing Term Guideline.

[12] Arai T, Kato R, Fujita M (2010) Assessment of Operator Stress Induced by Robot Collaboration in Assembly. Annals of the CIRP 59(1):5-8.

[13] Aras N, Aksen D (2008) Locating Collection Centers for Distance- and Incentive Dependent Returns. International Journal of Production Economics 111(2):316333.

[14] Ari V (2016) E-Waste in Transition - From Pollution to Resource - A Review of Technology of Metal Recovery from Electronic Waste, Intech.

[15] Ayvaz B, Boltürk E, Kaçt??ioğlu S (2014) A Grey System for the Forecasting of Return Product Quantity in Recycling Network. International Journal of Supply Chain Management 3(3):105-112.

[16] Aziz N-A, Wahab D-A, Ramli R, Azhari C-H (2016) Modelling and Optimisation of Upgradability in the Design of Multiple Life Cycle Products: A Critical Review. Journal of Cleaner Production 112(1):282-290.

[17] Avikal A, Jain R, Mishra P (2013) A Heuristic for U-shaped Disassembly Line Balancing Problems. International Journal of Mechanical Engineering 3(1):5156.

[18] Baiguera F, Colledani M (2016) A Knowledge-based Method for the Prediction of Valuable Materials in Waste Printed Circuit Boards. Proceeding of Third Symposium on Urban Mining.

[19] Bain P, Manfre G (2006), Method and apparatus for bonding and debonding adhesive interface surfaces, Patent.

[20] Barker S, King A (2007) Organising Reuse: Managing the Process of Design For Remanufacture (DFR). POMS 18th Annual Conference, Dallas, Texas, U.S.A.

[21] Barwood M, Li J, Pringle T, Rahimifard S (2015) Utilisation of Reconfigurable Recycling Systems for Improved Material Recovery from E-waste. Procedia CIRP 29:746-751.

[22] Basdere B, Seliger G (2003) Disassembly Factories for Electrical and Electronic Products To Recover Resources in Product and Material Cycles. Environmental Science and Technology 37(23):5354-5362.
[23] Bentaha M-L, Battaïa O, Dolgui A, Hu J (2014) Dealing with Uncertainty in Disassembly Line Design. Annals of the CIRP 63(1):21-24.

[24] Bentaha M-L, Battaïa O, Dolgui A (2014) A Sample Average Approximation Method for Disassembly Line Balancing Problem under Uncertainty. Computers E Operations Research 51:111-122.

[25] Bentaha M-L, Battaïa O, Dolgui A, Hu J (2015) Second Order Conic Approximation for Disassembly Line Design with Joint Probabilistic Constraints. European Journal of Operational Research 247(3):957-967.

[26] Bentaha M-L, Battaïa O, Dolgui A (2015) An Exact Solution Approach for Disassembly Line Balancing Problem under Uncertainty of the Task Processing Times. International Journal of Production Research 53(6):1807-1818.

[27] Bilge P, Badurdeen F, Seliger G, Jawahir I-S (2016) A Novel Manufacturing Architecture for Sustainable Value Creation. Annals of the CIRP 65(1):455-458.

[28] Bilgili E, Capece M (2011) Quantitative Analysis of Multi-particle Interactions During Particle Breakage: A Discrete Non-linear Population Balance Framework. Powder Technology 213(13):162-173.

[29] Bley H, Reinhart G, Seliger G, Bernardi M, Korne T (2004) Appropriate Human Involvement in Assembly and Disassembly. Annals of the CIRP 53(2):487-509.

[30] Borrotti M, Pievatolo A, Critelli I, Degiorgi A, Colledani M (2016) A Computeraided Methodology for the Optimization of Electrostatic Separation Processes in Recycling. Applied Stochastic Models in Business and Industry 32(1):133-148.

[31] Bouzon M, Rodriguez C-M, Queiroz A (2012) Cell Layout Applications in Product Recovery: A Lean Proposal to Increase Efficiency in in Remanufacturing. China Business Review 11(5):467-475.

[32] Castro M, Remmerswaal J, Brezet J, Van Schaik A, Reuter M (2005) A Simulation Model of the Comminution-liberation of Recycling Streams: Relationships Between Product Design and the Liberation of Materials During Recycling. International Journal of Mineral Processing 75:255-281. 3.

[33] Caterpillar Inc (2014) Core Acceptance Criteria.

[34] Charter M, Gray C (2008) Remanufacturing and Product Design. International Journal of Product Development 6(3-4):375-392.

[35] Chen C, Wang Y, Ou H, He Y, Tan Z (2014) A Review on Remanufacture of Dies and Molds. Journal of Cleaner Production 64:13-24.

[36] Chen Y-W, Wang L-C, Wang A, Chen T-L (2017) A Particle Swarm Approach for Optimizing a Multi-stage Closed Loop Supply Chain for the Solar Cell Industry. Robotics and CIM 43:111-123.

[37] Chertow M-R (2000) Industrial Symbiosis: Literature and Taxonomy. Annual Review of Environment and Resources 25(1):313-337.

[38] Chidi Nnorom I, Osibanjo O (2010) Overview of Prospects in Adopting Remanufacturing of End-of-life Electronic Products in the Developing Countries. International Journal of Innovation Management and Technology 1(3):328-338.

[39] Chierici E, Copani G (2016) Remanufacturing with Upgrade PSS for New Sustainable Business Models. Procedia CIRP 47:531-536.

[40] Chiodo J-D, Jones N, Billett E-H, Harrison D-J (2002) Shape Memory Alloy Actuators for Active Disassembly Using 'smart' Materials of Consumer Electronic Products. Materials \& Design 23:471-478.

[41] Choi J-N, Fthenakis V (2011) Design and Optimization of Photovoltaics Recycling Infrastructure. Environmental Science \& Technology 44:8678-8683.

[42] Clottey T, Benton W-C, Srivastava R (2012) Forecasting Product Returns for Remanufacturing Operations. Decision Science 43:589-614.

[43] Coates G, Rahimifard S (2009) Modelling of Post-fragmentation Waste Stream Processing Within UK Shredder Facilities. Waste Management 29:44-53.

[44] Colledani M, Tolio T (2005) A Decomposition Method to Support the Configuration/reconfiguration of Production Systems. Annals of the CIRP 54(1):441444.

[45] Colledani M, Tolio T (2013) Integrated Process and System Modelling for the Design of Material Recycling Systems. Annals of the CIRP 62(1):447-452.

[46] Colledani M, Copani G, Tolio T (2014) De-manufacturing Systems. Procedia CIRP 17:14-19.

[47] Colledani M, Critelli I, Degiorgi A, Tasora A (2014) Multi-body Granular Flow Simulation for the Design and Operation of Mechanical Separation Processes for Recycling. Proceeding of CARE Electronics. Nov 17-20, Wien, Austria.

[48] Colledani M, Battaya O (2016) A Decision Support System to Manage the Quality of End-of-life Products in Disassembly Systems. Annals of the CIRP 65 (1):41-44.

[49] Copani G, Brusaferri A, Colledani M, Pedrocchi N, Sacco M, Tolio T (2012) Integrated De-manufacturing Systems as New Approach to End-of-life Management of Mechatronic Devices. 10th CIRP Global Conference on Sustainable Manufacturing.

[50] Cui H, Anderson CG (2016) Literature Review of Hydrometallurgical Recycling of Printed Circuit Boards (PCBs). Journal of Advanced Chemical Engineering 6 (1):1-11.

[51] Cui J (2003) Mechanical Recycling of Waste Electric and Electronic Equipment: A Review. Journal of Hazardous Materials 99:243-263.

[52] Denizel M, Ferguson M, Souza G (2010) Multi-period Remanufacturing Planning with Uncertain Quality of Inputs. IEEE Transactions on Engineering Management 57(3):394-404

[53] Duflou J-R, Willems B, Dewulf W (2006) Towards Self-disassembling Products - Design Solutions for Economically Feasible Large-scale Disassembly. Innovation in Life Cycle Engineering and Sustainable Development, 87-110.

[54] Duflou J-R, Seliger G, Kara S, Umeda Y, Ometto A, Willems B (2008) Efficiency and Feasibility of Product Disassembly: A Case-based Study. Annals of the CIRP 57(2):583-600

[55] Duflou J-R, Sutherland JW, Dornfeld D, Herrmann C, Jeswiet J, Kara S, Haushild M, Kellens K (2012) Towards Energy and Resource Efficient Manufacturing: A Process and Systems Approach. Annals of the CIRP 61(2):587-609.

[56] Duflou J-R, Tekkaya A, Haaseb M, Weloc T, Vanmeenseld K, Kellensa K, Dewulf W, Paraskevasa D (2015) Environmental Assessment of Solid State Recycling Routes for Aluminium Alloys: Can Solid State Processes Significantly Reduce the Environmental Impact of Aluminium Recycling? Annals of the CIRP 64(1):37-40. 
[57] Duta L, Filip F-G, Popescu C (2008) Evolutionary Programming in Disassembly Decision Making. International Journal of Computers Communications \& Control 3:282-286.

[58] Eguia I, Lozano S, Racero J, Guerrero F (2011) A Methodological Approach for Designing and Sequencing Product Families in Reconfigurable Disassembly Systems. Journal of Industrial Engineering and Management 4(3):418-435.

[59] ElMaraghy H, Schuh G, ElMaraghy W, Piller F, Schonsleben P, Tseng M, Bernard A (2013) Product Variety Management. Annals of the CIRP 62(2): 629-652.

[60] ElMaraghy W, ElMaraghy H, Tomiyama T, Monostori L (2012) Complexity in Engineering Design and Manufacturing. Annals of the CIRP 2:793-814.

[61] ElSayed A, Kongar E, Gupta SM, Sobh T (2012) A Robotic-driven Disassembly Sequence Generator for End-of-life Electronic Products. Intelligent Robot Systems 68(1):43-52.

[62] Entezaminia A, Heydari M, Rahmani D-A (2016) A Multi-objective Model for Multi-product Multi-site Aggregate Production Planning in a Green Supply Chain: Considering Collection and Recycling Centers. Journal of Manufacturing Systems 40(1):63-75.

[63] Errington M, Childe S-J (2013) A Business Process Model of Inspection on Remanufacturing. Journal of Remanufacturing 3(7):1-22.

[64] EU FP7 HydroWEEE, Innovative Hydrometallurgical Processes to Recover Metals from WEEE Including Lamps and Batteries, GA 231962.

[65] EU FP7 Premanus, Product Remanufacturing Service System, GA 285541.

[66] EU FP7 RobustPlaNet, Shock-robust Design of Plants and their Supply Chain Networks, GA 609087.

[67] EU H2020 Screen, Synergic Circular Economy across European Regions, GA 730313.

[68] European Commission (2016) Better Regulations for Innovation-driven Investment at EU level Directorate-General for Research and Innovation.

[69] European Commission (2015) Closing the Loop - An EU Action Plan for the Circular Economy, Brussels, 2.12.2015 COM 614.

[70] European Remanufacturing Network (2015) Remanufacturing Market Study.

[71] Faccio M, Persona A, Sgarbossa F, Zanin G (2014) Sustainable SC through the Complete Reprocessing of End-of-life Products by Manufacturers: A Traditional versus Social Responsibility Company Perspective. European Journal of Operational Research 233(2):359-373.

[72] Ferguson M, Guide Jr V-D, Koca E, Van Souza G-C (2009) The Value of Quality Grading in Remanufacturing. Production and Operations Management 18:300314.

[73] Franke C, Basdere B, Ciupek M, Seliger G (2006) Remanufacturing of Mobile Phones - Mcapacity Program and Facility Adaptation Planning. Omega 34:562-570

[74] Freiberger S, Albrecht M, Käufl J (2011) Reverse Engineering Technologies for Remanufacturing of Automotive Systems Communicating via CAN Bus. Journal of Remanufacturing 1:6.

[75] Frosch R, Gallopoulos N (1989) Strategies for Manufacturing. Scientific American 261:144-152.

[76] Galbreth M-R, Blackburn J-D (2006) Optimal Acquisition and Sorting Policies for Remanufacturing. Production and Operations Management 15:384-392.

[77] Gamage J-R, Windmill J (2013) What Makes Cleaning a Costly Operation in Remanufacturing? 11th CIRP Global Conference on Sustainable Manufacturing.

[78] Gao J, Chen X, Yilmaz O, Gindy N (2008) An Integrated Adaptive Repai Solution for Complex Aerospace Components Through Geometry Reconstruction. International Journal of Advanced Manufacturing Technology 36:1170-1179.

[79] Gao W-J, Xing B (2013) Computational Intelligence in Remanufacturing, IG Publishing, Hershey.

[80] Gaoa W, Zhang Y, Ramanujan D, Ramani K, Chen Y (2015) The Status, Challenges, and Future of Additive Manufacturing in Engineering. Computer-Aided Design 69:65-89.

[81] Garcia-Hernandez L, Arauzo-Azofra A, Salas-Morera L, Pierreval H, Corchado E (2013) Recycling Plants Layout Design by Means of an Interactive Genetic Algorithm. Intelligent Automation and Soft Computing 19(3):457-468.

[82] Ghisellini P, Cialani C, Ulgiati S (2016) A Review on Circular Economy: The Expected Transition to a Balanced Interplay of Environmental and Economic Systems. Journal of Cleaner Production 114:11-32.

[83] Go T-F, Wahab D-A, Rahman MN-A, Ramli R, Azhari C-H (2011) Disassemblability of End-of-life Vehicle: A Critical Review of Evaluation Methods. Journal of Cleaner Production 19:1536-1546.

[84] Govindan K, Soleimani H (2017) A Review of Reverse Logistics and Closed-loop Supply Chains: A Journal of Cleaner Production Focus. Journal of Cleaner Production 142(1):371-384.

[85] Guidat T, Barquet A-P, Widera H, Rozenfeld H, Seliger G (2014) Guidelines for the Definition of Innovative Industrial Product-Service Systems (PSS) Business Models for Remanufacturing. Procedia CIRP 16:193-198.

[86] Guidat T, Seidel J, Kohl H, Seliger G (2017) A Comparison of Best Practices of Public and Private Support Incentives for the Remanufacturing Industry. 24th CIRP Conference in Life Cycle Engineering, March 8th-10th, Kamakura, Japan.

[87] Guidat T, Uoti M, Tonteri H, Määttä T (2015) A Classification of Remanufacturing Networks in Europe and their Influence on New Entrants. Procedia CIRP 26:683-688.

[88] Guide V, Van Wassenhove L (2001) Managing Product Returns for Remanufacturing. Production and Operations Management 10:142-155.

[89] Güngör A, Gupta S-M (1997) An Evaluation Methodology for Disassembly Processes. Proc 21st Int Conf Comput Ind Eng 33(1):329-332.

[90] Güngör A, Gupta S-M (2002) Disassembly Line in Product Recovery. International Journal of Production Research 40(11):2569-2589.

[91] Gutowski T, Dahmus J, Albino D, Branham M (2007) Bayesian Material Separation Model with Applications to Recycling. IEEE International Symposium on Electronics and the Environment 233-238.
[92] Habibi M-K, Battaïa O, Cung ?D V, Dolgui A (2017) Collection-Disassembly Problem in Reverse Supply Chain. International Journal of Production Economic 183:334-344.

[93] Hamano K (2011) Material Separation and Recycling of Mixed and Shredded Plastics from Used Household Appliances. Gpec2011 - Global Plastics Environ Conf.

[94] Hanafi J, Kara S, Kaebernick H (2007) Generating Fuzzy Colored Petri Net Forecasting Model to Predict the Return of Products. Proceedings of the IEEE International Symposium on Electronics and the Environment.

[95] Hanafi J, Kara S, Kaebernick H (2008) Analysis of Collection Network Strategy Applications to End-of-life Electronics. Proceedings of the 15th CIRP International Conference in Life Cycle Engineering, 11-13 June, Sydney, Australia.

[96] Hanafi J, Kara S, Kaebernick H (2008) Reverse Logistic Strategies for End of Life Products. International Journal of Logistics Management 19(3):367-388.

[97] Hartwell I, Marco J (2016) Management of Intellectual Property Uncertainty in a Remanufacturing Strategy for Automotive Energy Storage Systems. Journal of Remanufacturing 6:3.

[98] Hatcher G-D, Ijomah W-L, Windmill JF-C (2011) Design for Remanufacture: A Literature Review and Future Research Needs. Journal of Cleaner Production 19:2004-2014

[99] Hatcher G-D, Ijomah W-L, Windmill JF-C (2013) Integrating Design for Remanufacture into the Design Process: The Operational Factors. Journal of Cleaner Production 39:200-208.

[100] Hauschild M, Jeswiet J, Alting L (2005) From Life Cycle Assessment to Sustainable Production: Status and Perspectives. Annals of the CIRP 54(2): $1-21$.

[101] Herrmann C, Raatz A, Andrew S, Schmitt J (2014) Scenario-Based Development of Disassembly Systems for Automotive Lithium Ion Battery Systems. Advanced Materials Research 907:391-401.

[102] Hoque M, Sokhansanj S, Naimi L, Bi X, Lim J, Womac A-R (2007) Review and Analysis of Performance and Productivity of Size Reduction Equipment for Fibrous Materials. Proceeding of 2007 ASABE Annual International Meeting 1-18.

[103] Hu J, Ko J, Weyand L, ElMaraghy H-A, Lien T-K, Koren Y, Shpitalni M (2011) Assembly System Design and Operations for Product Variety. Annals of the CIRP 60(2):715-733.

[104] Hubbard G (2009) Measuring Organizational Performance: Beyond the Triple Bottom Line. Business Strategy and the Environment 3:177-191.

[105] http://www.ricoh.com/environment/management/concept.html (Accessed January 2017).

[106] http://www.ricoh.com/environment/strategy/target.html (Accessed January 2017).

[107 Hui W, Dong X, Guanghong D (2008) A Genetic Algorithm for Product Disassembly Sequence Planning. Artificial Neural Networks 71(13-15):27202726.

[108] Huisman S, Debaveyea S, Schaubroecka T, De Meestera S, Ardente F, Mathieux F, Dewulf J (2015) The Recyclability Benefit Rate of Closed-loop and Openloop Systems: A Case Study on Plastic Recycling in Flanders. Resource Conservation and Recycling 101:53-60.

[109] Ibbotson S, Kara S, Kaebernick H (2007) A Methodology to Analyse the Critical Design Parameters for Reuse. International Journal of Environmentally Conscious Design \& Manufacturing 13(3-4).

[110] Ignatenko O, van Schaik A, Reuter M (2008) Recycling System Flexibility: The Fundamental Solution to Achieve High Energy and Material Recovery Quotas. Journal of Cleaner Production 16:432-449.

[111] Ilyas S, Lee J-C (2014) Biometallurgical Recovery of Metals from Waste Electrical and Electronic Equipment: A Review. ChemBioEng Reviews 1(4).

[112] Ilgin M-A, Gupta S-M (2010) Environmentally Conscious Manufacturing and Product Recovery (ECMPRO): A Review of the State of the Art. Journal of Environmental Management 91(3):563-591.

[113] Ilgin M-A, Gupta S-M (2011) Performance Improvement Potential of Sensor Embedded Products in Environmental Supply Chains. Resource Conservation and Reycling 6:580-592.

[114] Ijomah W-L, McMahon C, Hammond G, Newman S (2007) Development of Design for Remanufacturing Guidelines to Support Sustainable Manufacturing. Robotics and Computer Integrated Manufacturing 23:712-719.

[115] Ijomah W-L, McMahon C, Hammond G, Newman S (2007) Development of Robust Design-for Remanufacturing Guidelines to Further the Aims of Sustainable Development. International Journal of Production Research 45 (18):4513-4536

[116] Ijomah W-L (2009) Addressing Decision Making for Remanufacturing Operations and Design-for-remanufacture. International Journal of Sustainable Engineering 2(2):91-202.

[117] Ijomah W-L (2008) A Tool to Improve Training and Operational Effectiveness in Remanufacturing. International Journal of Computer Integrated Manufacturing 21(6):676-701.

[118] ISO/TS 15066, Robots and Robotic Devices-Safety Requirements for Industrial Robots-Collaborative Operation, ISO TC184/SC2, 2015.

[119] Jaehn F (2016) Sustainable Operations. European Journal of Operational Research 253:243-264.

[120] Jayal A-D, Badurdeen F, Dillon O-W, Jawahir I-S (2010) Sustainable Manufacturing: Modeling and Optimization Challenges at the Product, Process and System Levels. CIRP Journal of Manufacturing Science and Technology 2(3):144-152.

[121] Jawahir I-S, Bradley R (2016) Technological Elements of Circular Economy and the Principles of 6R-Based Closed-loop Material Flow in Sustainable Manufacturing. Procedia CIRP 40:103-108.

[122] Jeihoonian M, Kazemi Z, Gendreau M (2016) Accelerating Benders Decomposition for Closed-loop Supply Chain Network Design: Case of Used Durable Products with Different Quality Levels. European Journal of Operational Research 251(3):830-845 
[123] Jiang Z, Zhang H, Sutherland J-W (2011) Development of Multi-criteria Decision Making Model for Remanufacturing Technology Portfolio Selection. Journal of Cleaner Production 19:1939-1945.

[124] Jiang Z, Zhou T, Zhang H, Wang Y, Cao H, Tian G (2016) Reliability and Cost Optimization for Remanufacturing Process Planning. Journal of Cleaner Production 135:1602-1610.

[125] Jin X, Hu J, Koren Y (2011) Optimal Control of Reassembly with Variable Quality Returns in a Product Remanufacturing System. Annals of the CIRP 60 (1):25-28.

[126] Jindal A, Sangwan K-S, Saxena S (2016) Network Design and Optimization for Multi-product, Multi-time, Multi-echelon Closed-loop Supply Chain under Uncertainty. Procedia CIRP 29:656-661.

[127] Jovane F, Alting L, Armillotta A, Eversheim W, Feldmann K, Seliger G, Roth N (1993) A Key Issue in Product Life-cycle: Disassembly. Annals of the CIRP 42 (2):651-658

[128] Jovane F, Yoshikawa H, Alting L, Boër C-R, Westkamper E, Williams D, Tseng M, Seliger G, Paci A-M (2008) The Incoming Global Technological and Industrial Revolution towards Competitive Sustainable Manufacturing. Annals of the CIRP 2:641-659.

[129] Junior M-L, Filho M-G (2012) Production Planning and Control for Remanufacturing: Literature Review and Analysis. Production Planning and Control 6:419-435.

[130] Kang J-G, Lee D-H, Xirouchakis P, Persson J-G (2001) Parallel Disassembly Sequencing with Sequence-Dependent Operation Times. Annals of the CIRP 50 (1):343-346

[131] Kakafu J-M, Mat Saman M-Z, Yusof S, Sharif S, Zakuan N (2015) Investment Decision Issues from Remanufacturing System Perspective: Literature Review and Further Research. Procedia CIRP 26:589-594.

[132] Kalayci C-B, Gupta S-M (2014) A Tabu Search Algorithm for Balancing a Sequence-dependent Disassembly Line. Production Planning and Control 25 (2):149-160

[133] Kara S, Mazhar I-M, Kaebernick H (2004) Lifetime Prediction of Components for Reuse: An Overview. International Journal of Environment and Technology 4 (4):323-348.

[134] Kara S, Mazhar MI, Kaebernick H, Ahmed H (2005) Determining the Reuse Potential of Components Based on Life Cycle Data. Annals of the CIRP 54(1):1-

[135] Kara S, Pornprasitpol P, Kaebernick H (2005) A Methodology for Selective Disassembly for End-of-life (EOL) Products. Journal of Assembly Automation 25 (2):124-134

[136] Kara S, Pornprasitpol P, Kaebernick H (2006) Selective Disassembly Sequencing: A Methodology for the End-of-life Products. Annals of the CIRP 55(1):3740.

[137] Kara S, Rugrungruang F, Kaebernick H (2007) Simulation Modelling of Reverse Logistics Networks. International Journal of Production Economics 106:61-69.

[138] Kara S, Manmek S, Kaebernick H, Ibbotson I (2008) Assessment of Products for Minimal Manufacturing. Annals of the CIRP 57(1):1-4.

[139] Kara S (2010) Assessing Remaining Useful Lifetime. Wiley Encyclopedia of Operations Research and Management Science, 1-14.

[140] Kawaguchi Y (2004) Synthesis and Properties of Thermoplastic Expandable Microspheres: The Relation Between Crosslinking Density and Expandable Property. Journal of Applied Polymer Science 93(2):505-512.

[141] Kernbaum S, Heyer S, Chiotellis S, Seliger G (2009) Process Planning for ITequipment Remanufacturing. CIRP Journal of Manufacturing Science and Technology 2:13-20.

[142] Khaliq A, Rhamdhani M-A, Brooks G, Masood S (2014) Metal Extraction Processes for Electronic Waste and Existing Industrial Routes: A Review and Australian Perspective. Resources 3:152-179.

[143] Kim H-J, Kernbaum S, Seliger G (2009) Emulation-based Control of a Disassembly System for LCD Monitors. International Journal of Advanced Manufacturing Technology 40:383-392.

[144] Kimura F, Kato S, Hata T, Masuda T (2001) Product Modularization for Parts Reuse in Inverse Manufacturing. Annals of the CIRP 50(1):89-92.

[145] Kin S-T, Ong S-K, Nee A-Y (2014) Remanufacturing Process Planning. Procedia CIRP 15:189-194

[146] King A, Burgess S (2005) The Development of a Remanufacturing Platform Design: A Strategic Response to the Directive on Waste Electrical and Electronic Equipment. Proceedings of the IMechE 219/B:623-631.

[147] King A, Burgess S, Ijomah W-L, McMahon C-A (2006) Reducing Waste: Repair, Recondition, Remanufacture or Recycle? Sustainable Development 14:257-267.

[148] Koc A, Sabuncuoglu I, Erel E (2009) Two Exact Formulations for Disassembly Line Balancing Problems with Task Precedence Diagram Construction Using an AND/OR Graph. IIE Transactions 41(10):866-881.

[149] Köhler DC-F, Merwerth F (2014) Mechatronic Remanufacturing at KnorrBremse Commercial Vehicles Systems (CVS). in Weiland F-JRemanufacturing of Heavy Duty Vehicle Components - A Hidden Giant,

[150] Köhler DC-F (2012) Regenerative (Remanufacturing) Supply Chains $\mathrm{CO}_{2}$ Footprints of Automotive Supply Chains and $\mathrm{CO}_{2}$-Savings of Regenerated Parts. in Weiland F-JEuropean Automotive Remanufacturing-Technical Trends \& Market Development,

[151] Kondoh S, Soma M, Umeda Y (2007) Simulation of Closed-loop Manufacturing Systems Focused on Material Balance of Forward and Inverse Flows. International Journal of Environmentally Design \& Manufacturing 13(2):1-16.

[152] Kongar E, Gupta S-M (2002) Genetic Algorithm for Disassembly Process Planning. Proc SPIE 4569 Env Conscious Manufacturing II 54-62.

[153] Kongar E, Gupta S-M (2002) A Multi-criteria Decision Making Approach for Disassembly-to-order Systems. Journal of Electronics Manufacturing 11(2): 171-183.

[154] Kopacek P, Kopacek B (2006) Intelligent, Flexible Disassembly. International Journal Advanced Manufacturing Technology 30:54-560.
[155] Koren Y, Heisel U, Jovane F, Moriwaki T, Pritschow G, Ulsoy G, Brussel H-V (1999) Reconfigurable Manufacturing Systems. Annals of the CIRP 48(2):527540.

[156] Koren Y, Hu S-J, Gu P, Shpitalni M (2013) Open-architecture Products. Annals of the CIRP 62(2):719-729.

[157] Kott N (2003), Fastener system, Patent.

[158] Kristianto Y, Helo P (2015) Product Architecture Modularity Implications for Operations Economy of Green Supply Chains. Transportation Research Part E: Logistics and Transportation Review 74:63-80.

[159] Kruger J, Lien T-K, Verl A (2009) Cooperation of Human and Machines in Assembly Lines. Annals of the CIRP 58(2):628-646.

[160] Lage M, Godinho M (2012) Production Planning and Control for Remanufacturing: Literature Review and Analysis. Production Planning and Control 23:419-435.

[161] Lambert AJ-D (2006) Exact Methods in Optimum Disassembly Sequence Search for Problems Subject to Sequence Dependent Costs. Omega 34:538-549.

[162] Lambert AJ-D (2007) Optimizing Disassembly Processes Subjected to Sequence-dependent Cost. Computers \& Operations Research 34:536-551.

[163] Lambert FJ-D, Gupta S (2008) Methods for optimum and near optimum disassembly sequencing. International Journal Production Research 46: 2845-2865.

[164] Le Digue J, Gulbrandsen-Dahl S, Vallet F, Soderberg R, Eynard B, Perry N (2016) Optimization and Lifecycle Engineering for Design and Manufacture of Recycled Aluminium Parts. Annals of the CIRP 65(1):149-152.

[165] Levänen J, Lindemann S (2016) Frugal Innovations in Circular Economy: Exploring Possibilities and Challenges in Emerging Markets. The International Society for Ecological Economics Conference.

[166] Li W-D, Xia K, Gao L, Chao K-M (2013) Selective Disassembly Planning for Waste Electrical and Electronic Equipment with Case Studies on Liquid Crystal Displays. Robotics and Computer-Integrated Manufacturing 29 (4):248-260

[167] Li C-B, Tang Y, Li C-C (2011) A GERT-based Analytical Method for Remanufacturing Process Routing. Autom Science and Eng (CASE) 462-467.

[168] Li C-B, Tang Y, Li C-C, Li L-L (2013) A Modeling Approach to Analyze Variability of Remanufacturing Process Routing. IEEE Transactions on Automation Science and Engineering 1:86-98.

[169] Liang X, Jin X, Ni J (2014) Forecasting Product Returns for Remanufacturing Systems. Journal of Remanufacturing 4(8).

[170] Liu W, Zhang B, Zheng Li M, Li Zhang YH (2013) Study on Remanufacturing Cleaning Technology in Mechanical Equipment Remanufacturing Process. 20th CIRP International Conference on Life Cycle Engineering, Singapore.

[171] Lu Q, Stuart Williams J-A, Posner M, Bonawitan W, Qu X (2006) Model-based Analysis of Capacity and Service Fees for Electronics Recyclers. Journal of Manufacturing Systems 1:45-57.

[172] Lukka T-J, Tossavainen T, Kujala J-V, Raiko T (2014) ZenRobotics RecyclerRobotic Sorting Using Machine Learning. Sensor Based Sorting.

[173] Lutters E, Van Houten FJA-M, Bernard A, Mermoz E, Schutte CS-L (2014) Tools and Technics for Product Design. Annals of the CIRP 63(2):607-630.

[174] Lyle J-T (1996) Regenerative Design for Sustainable Development, Wiley Ed..

[175] MacArthur Foundation (2013) Towards the Circular Economy: Economic Business Rationale for an Accelerated Transition.

[176] MacArthur Foundation (2013) Towards the Circular Economy: Opportunities for the Consumer Goods Sector.

[177] MacArthur Foundation (2015) Growth Within: A Circular Economy Vision for a Competitive Europe.

[178] Macko M (2016) Post-consumer Waste Recycling and Optimal Production - Size Reduction by Grinding as an Important Stage in Recycling, Intech.

[179] Maraspin F, Bevilacqua P, Rem P (2004) Modeling the Throw of Metals and Non-metals in Eddy Current Separation. International Journal of Mineral Processing 73:1-11.

[180] Marx-Gomez J, Rautenstrauch C, Nornberger A, Kruse R (2002) Neuro-fuzzy Approach to Forecast Returns of Scrapped Products to Recycling and Remanufacturing. Knowledge-Based Systems 15(1):119-128.

[181] Marvel J (2013) Performance Metrics of Speed and Separation Monitoring in Shared Workspaces. IEEE Transactions on Automation Science and Engineering 2:405-414.

[182] Matsumoto M, Ikeda A (2015) Examination of Demand Forecasting by Time Series Analysis for Auto Parts Remanufacturing. Journal of Remanufacturing 5:1-20.

[183] Matsumoto M, Komatsu S (2015) Demand Forecasting for Production Planning in Remanufacturing. International Journal Advanced Manufacturing Technology 79(1):161-175.

[184] Matsumoto M, Umeda Y, Tsuchiya S, Tang L (2016) Development of Demand Forecasting Model for Automotive Electric Component Remanufacturing. Electronics Goes Green EGG Conference, Berlin, Germany.

[185] Matsumoto M, Yang S, Martinsen K, Kainuma Y (2016) Trends and Research Challenges in Remanufacturing. International Journal of Precision Engineering and Manufacturing-Green Technology 3(1):129-142.

[186] Mazhar M-I, Kara S, Kaebernick H (2007) Remaining Life Estimation of Used Components in Consumer Products: Life Cycle Data Analysis by Weibull and Artificial Neural Networks. Journal of Operations Management 25(6):11841193.

[187] McDonough W, Braungart M (2002) Cradle to Cradle: Remaking the Way We Make Things, North Point Press, New York.

[188] Meier H, Roy R, Seliger G (2010) Industrial Product-Service Systems-IPSS. Annals of the CIRP 59(2):607-627.

[189] Merdan M, Lepuschitz W, Meurer T, Vincze M (2010) Towards Ontology-based Automated Disassembly Systems. IECON 2010-36th Annual Conference on IEEE Industrial Electronics Society 1392-1397. 
[190] Michalos G, Makris S, Tsarouchi P, Guasch T, Kontovrakis D, Chryssolouris C (2015) Design Considerations for Safe Human-robot Collaborative Workplaces. Procedia CIRP 37:248-253.

[191] Mirmajlesi S-R, Shafaei R (2016) An Integrated Approach to Solve a Robust Forward/reverse Supply Chain for Short Lifetime Products. Computers \& Industrial Engineering 97:222-239.

[192] Morgan S-D, Gagnon R-J (2013) A Systematic Literature Review of Remanufacturing Scheduling. International Journal of Production Research 51 (16):4853-4879

[193] Monostori L, Kádár B, Bauernhsansl T, Kondoh S, Kumara S, Reinhart G, Sauer O, Schuh G, Sihn W, Ueda K (2016) Cyber-physical Systems in Manufacturing. Annals of the CIRP 65(2):621-641.

[194] Nahas N, Nourelfath M, Gendreau M (2014) Selecting Machines and Buffers in Unreliable Assembly/disassembly Manufacturing Networks. International Journal of Production Economics 154:113-126.

[195] Nan L, Liu W, Zhang K (2011) Laser Remanufacturing Based on the Integration of Reverse Engineering and Laser Cladding. International Journal of Computer Applications in Technology 37(2):116-124.

[196] Nasr N, Hughson C, Varel E, Bauer R (1998) State-of-the-art Assessment of Remanufacturing Technology, Rochester Institute of Technology.

[197] Navrotsky (2014) 3D printing at Siemens Power Service, Siemens.

[198] Newman S, Zhu A, Dhokia V, Shokrani A (2015) Process Planning for Additive and Subtractive Manufacturing Technologies. Annals of the CIRP 64(1):467-470.

[199] Nick J, Harrison D, Hussein H, Billett E, Chiodo J (2003) Towards Selfdisassembling Vehicles. Journal of Sustainable Product Design 3:59-74.

[200] Nishino N, Wang S, Tsuji N, Kageyama K, Ueda K (2012) Categorization and Mechanism of Platform-type Product-service Systems in Manufacturing. Annals of the CIRP 61(1):391-394.

[201] Osterwalder A, Pigneur Y, Clark T (2010) Business Model Generation: A Handbook for Visionaries, Game Changers, and Challengers, John Wiley \& Sons.

[202] Östlin J, Sundin E, Björkman M (2008) Business Drivers for Remanufacturing. Proceedings of CIRP Life Cycle Engineering Seminar 581-586.

[203] Östlin J, Sundin E, Björkman M (2009) Product Life-cycle Implications for Remanufacturing Strategies. Journal of Cleaner Production 17(11):999-1009.

[204] Özdemir Ö., Denizel M-V, D.-R Jr ie. (2012) Recovery Decisions of a Produce in a Legislative Disposal Fee Environment. European Journal of Operational Research 216:293-300.

[205] Papakostas N, Pintzos G, Triantafyllou C (2016) Computer-aided Design Assessment of Products for End of Life Separation and Material Handling. Annals of the CIRP 64(1):185-188.

[206] Parker D (2007) An Analysis of the Spectrum of Re-use, Oakdene Hollins Ltd. for Defra, Aylesbury.

[207] Parkinson H-J, Thompson G (2003) Analysis and Taxonomy of Remanufacturing Industry Practice. Proceedings of the Institution of Mechanical Engineers 217:243-256

[208] Parkinson H-J, Thompson G (2004) Systematic Approach to the Planning and Execution of Product Remanufacture. Journal of Process Mechanical Engineering 218:1-13.

[209] Pauli G (2010) The Blue Economy: 10 Years, 100 Innovations, 100 Million Jobs, Paradigm Publications, New Mexico.

[210] Peeters J, Van den Bossche W, Devoldere T, Vanegas P, Dewulf W, Duflou ] (2015) Pressure-sensitive Fasteners for Active Disassembly. The International Journal of Advanced Manufacturing Technology 87(5):1519-1529.

[211] Peeters J, Vanegas P, Dewulf W, Duflou J-R (2017) Economic and Environmental Evaluation of Design for Active Disassembly. Journal of Cleaner Production 140:1182-1193.

[212] Peeters J-R, Vanegas P, Van den Bossche W, Devoldere T, Dewulf W, Duflou J (2015) Elastomer-based Fastener Development to Facilitate Rapid Disassembly for Consumer Products. Journal of Cleaner Production 94:177-186.

[213] Peeters J, Vanegas P, Duflou J-R, Mizunoc T, Fukushige S, Umedac Y (2013) Effects of Boundary Conditions on the End-of-life Treatment of LCD TVs. Annals of the CIRP 62(1):35-38.

[214] Pellegrinelli S, Moro F-L, Pedrocchi N, Molinari Tosatti L, Tolio T (2016) A Probabilistic Approach to Workspace Sharing for Human-robot Cooperation in Assembly Tasks. Annals of the CIRP 65(1):57-60.

[215] Perry N, Bernard A, Laroche F, Pompidou S (2012) Improving Design for Recycling - Application to Composites. Annals of the CIRP 61(1):151-154.

[216] Pialot O, Millet D, Bisiaux J (2017) Upgradable PSS: Clarifying a New Concept of Sustainable Consumption/production Based on Upgradablility. Journal of Cleaner Production 141:538-550.

[217] Pialot O, Millet D, Tchertchian N (2012) How to Explore Scenarios of Multiple Upgrade Cycles for Sustainable Product Innovation: The upgrade Cycle Explorer Tool. Journal of Cleaner Production 22(1):19-31.

[218] Picón A, Ghita O, Bereciartua A, Echazarra J, Whelan P-F, Iriondo P-M (2012) Real-time Hyperspectral Processing for Automatic Nonferrous Material Sorting. Journal of Electronic Imaging 21(1).

[219] Picón A, Ghita O, Whelan P-F, Iriondo P-M (2009) Fuzzy Spectral and Spatial Feature Integration for Classification of Nonferrous Materials in Hyperspectral Data. IEEE Transactions on Industrial Informatics 5(4):483-494.

[220] Picone N, Colledani M, Copani G, Diani M, Tolio T (2016) Towards Smart Ewaste demanufacturing systems exploiting Cyber-physical Systems (CPSs) capabilities. Electronic Goes Green-EGG, Berlin.

[221] Polotski V, Kenne J-P, Gharbi A (2015) Optimal Production Scheduling for Hybrid Manufacturing-remanufacturing Systems with Setups. Journal of Manufacturing Systems 37(3):703-714.

[222] Presley A, Meade L, Sarkis J (2007) A Strategic Sustainability Justification Methodology for Organizational Decisions: A Reverse Logistics Illustration. International Journal of Production Research 18(19):4595-4620.

[223] Priyono A, Ijomah W, Bititci U (2016) Disassembly for Remanufacturing: A Systematic Literature Review, New Model Development and Future Research Needs. Journal of Industrial Engineering and Management 9(4):899-932.
[224] Pugliesi-Conti J, Girardiere C (1990), Snap-fit device for holding two parts together, Patent.

[225] Qu X, Williams JA-S (2008) An Analytical Model for Reverse Automotive Production Planning and Pricing. European Journal of Operational Research 190:756-767.

[226] Rahimifard S, Abu Bakar M-S, Williams D-J (2009) Recycling Process Planning for the End-of-life Management of Waste from Electrical and Electronic Equipment. Annals of the CIRP 58(1):5-8.

[227] Realff M-J, Ammons J-C, Newton D (2004) Robust Reverse Production System Design for Carpet Recycling. IIE Transactions 36(8):767-776.

[228] Ren GG-M (2007) Servitization in Manufacturing Companies. Cranfield Product-Service Systems Seminar 4-7.

[229] Reuter M-A, van Schaik A (2012) Opportunities and Limits of Recycling: A Dynamic-model-based Analysis. MRS Bulletin 37(4):339-347.

[230] Reuter M-A, van Schaik A, Gediga J (2015) Simulation-based Design for Resource Efficiency of Metal Production and Recycling Systems, Cases: Copper Production and Recycling, E-waste (LED Lamps), Nickel Pig Iron. International Journal of Life Cycle Assessment 20(5):671-693.

[231] Ridley S, Ljomah W-L (2015) A Novel Pre-processing Inspection Methodology to Enhance Productivity in Automotive Product Remanufacture: an Industrybased Research of 2196 Engines. Journal of Remanufacturing 5:8.

[232] Riggs R-J, Battaïa O, Hu J (2015) Disassembly Line Balancing under High Variety of End of Life States Using a Joint Precedence Graph Approach. Journal of Manufacturing Systems 37:638-648.

[233] Rocchetti L, Vegliò F, Kopacek B, Beolchini F (2013) Environmental Impact Assessment of Hydrometallurgical Processes for Metal Recovery from WEEE Residues Using a Portable Prototype Plant. Environmental Science and Technology 47:1581-1588.

[234] Rotter V-S, Chancerel P, Ueberschaar M (2013) Recycling-oriented Product Characterization for Electric and Electronic Equipment as a Tool to Enable Recycling of Critical Metals. Enabling Materials Resource Sustainability, Rewas, $192-201$.

[235] Sabanci zer H (2012) A Review of the Literature on Process Innovation in Remanufacturing. International Review of Management and Marketing 2(3): 139-155.

[236] Sabbaghi M, Esmaeilian B, Mashhadi A, Behdad S, Cade W (2015) An Investigation of Used Electronics Return Flows: A Data-driven Approach to Capture and Predict Consumers Storage and Utilization Behavior. Waste Management 36:305-315.

[237] Sakai T, Takata S (2011) Systematic Categorization of Reuse and Identification of Issues in Reuse Management in the Closed Loop Manufacturing. Procedia CIRP 425-430.

[238] Sakai T, Takata S (2012) Reconfiguration Management of Remanufactured Products for Responding to Varied User Needs. Annals of the CIRP 61:21-26.

[239] Santochi M, Dini G, Failli F (2002) Computer Aided Disassembly Planning: State of the Art and Perspectives. Annals of the CIRP 51(2):507-529.

[240] Scharke H (2003) Comprehensive Information Chain for Automated Disassembly of Obsolete Technical Appliances, GITO mbH Verlag.

[241] Schubert G, Bernotat S (2004) Comminution of Non-brittle Materials. International Journal of Mineral Processing 74:19-30.

[242] Seliger G, Basdere B, Keil T, Rebafka U (2002) Innovative Processes and Tools for Disassembly. Annals of the CIRP 51(2):37-40.

[243] Seliger G (2007) Sustainability in Manufacturing, Springer, Berlin Ed.

[244] Seliger G, Zettl M (2008) Modularization as an Enabler for Cycle Economy Annals of the CIRP 57(1):133-136.

[245] Shamsudin S, Lajis M-A, Zhong Z-W (2016) Solid-state Recycling of Light Metals: A Review. Advances in Mechanical Engineering 8(8):1-23.

[246] Shimomura Y, Umeda Y, Tomiyama T (1999) A Proposal of Upgradable Design. Proceedings of First International Symposium on Environmentally Conscious Design and Inverse Manufacturing 1000-1004.

[247] Simic V, Dimitrijevic B (2012) Production Planning for Vehicle Recycling Factories in the EU Legislative and Global Business Environments. Resources Conservation and Recycling 60:78-88.

[248] Smith S, Yen C-C (2010) Green Product Design Through Product Modularization Using Atomic theory. Robotics and Computer-Integrated Manufacturing 26(6):790-798.

[249] Sodhi M-S, Young J, Knight W-A (1999) Modelling Material Separation Processes in Bulk Recycling. International Journal of Production Research 37:2239-2252

[250] Soleimani H, Govindan K (2014) Reverse Logistics Network Design and Planning Utilizing Conditional Value at Risk. European Journal of Operational Research 237(2):487-497.

[251] Stahel W, Reday G (1981) Jobs for Tomorrow, the Potential for Substituting Manpower for Energy, Vantage Press, N.Y.

[252] Stark R, Grosser H, Muller P (2013) Product Analysis Automation for Digital MRO Based on Intelligent 3D Data Acquisition. Annals of the CIRP 62(1):123126.

[253] Su B, Heshmati A, Geng Y (2013) A Review of the Circular Economy in China: Moving from Rhetoric to Implementation. Journal of Cleaner Production 42:215-227.

[254] Subramoniam R, Huisingh D, Chinnam R-B (2010) Remanufacturing for the Automotive Aftermarket-strategic Factors: Literature Review and Future Research Needs. Journal of Cleaner Production 17:1163-1174.

[255] Subulan K, Taan A-S, Baykasog?lu A (2015) A Fuzzy Goal Programming Model to Strategic Planning Problem of a Lead/acid Battery Closed-loop Supply Chain. Journal of Manufacturing Systems 37(1):243-264

[256] Sundin E (2004) Product and Process Design for Successful Remanufacturing Linköping Studies in Science and Technology, PhD Dissertation.

[257] Sundin E, Lindahl M (2008) Rethinking Product Design for Remanufacturing to Facilitate Integrated Product Service Offerings. IEEE International Symposium on Electronics and the Environment. 
[258] Sundin E, Björkman M, Eklund M, Eklund J, Engkvist I-L (2011) Improving the Layout of Recycling Centres by Use of Lean Production Principles. Waste Management 31(6):1121-1132.

[259] Sundin E, Kristofer E, Lee H Mien (2012) Design for Automatic End-of-life Processes. Assembly Automation 32(4):389-398.

[260] Takata S, Sakai T (2009) Modelling Product Returns Taking Sales Modes into Account. International Journal of Automation Technology 3:71-76.

[261] Takata S, Tsubouchib K (2009) Maximizing Utilization Rate of Office Automation Equipment by Intraoffice Circulation. Annals of the CIRP 58(1):33-36.

[262] Takata S, Tsubouchi K, Yoshijima S (2009) Exhausting Lifetime by Multitiered Reuse with Forced Circulation in Closed-loop Manufacturing. International Journal of Sustainable Manufacturing 1(4):450-462.

[263] Takata S (2013) Maintenance-centered Circular Manufacturing. Procedia CIRP $11: 23-31$.

[264] Tchertchian N, Millet D, El Korchi A (2012) Design for Remanufacturing: What Performances Can Be Expected? International Journal of Environmental Technology and Management 15(1):28-49.

[265] Teunter R-H, Flapper S (2011) Optimal Core Acquisition and Remanufacturing Policies under Uncertain Core Quality Fractions. European Journal of Operational Research 210(2):241-248.

[266] Thompson M-K, Moroni G, Vaneker T, Fadel G, Campbell R-I, Gibson I, Bernard A, Schulz J, Graf P, Ahuja B, Martina F (2016) Design for Additive Manufacturing: Trends, Opportunities, Considerations, and Constraints. Annals of the CIRP 65(2):737-760

[267] Tolio T (2009) Design of Flexible Manufacturing Systems, Springer.

[268] Tolio T, Ceglarek D, Elmaraghy H-A, Fischer A, Hu J, Laperriere L, Newman S-T, Vancza J (2010) SPECIES-co-evolution of Products, Processes and Production Systems. Annals of the CIRP 59(2):672-693.

[269] Torres F (2004) Automatic PC Disassembly for Component Recovery. The International Journal of Advanced Manufacturing Technology 23(1):39-46.

[270] Tsang Mang Kin S, Ong S-K, Nee AY-C (2014) Remanufacturing Process Planning. Procedia CIRP 15:189-194.

[271] Tuncel E, Zeid A, Kamarthi S (2012) Solving Large-scale Disassembly Line Balancing Problem with Uncertainty Using Reinforcement Learning. Journal of Intelligent Manufacturing 2:1-13.

[272] Ueda K, Nishino N, Nakayama H, Oda S-H (2005) Decision Making and Institutional Design for Product Lifecycle Management. Annals of the CIRP 54(1):407-412.

[273] Ueda K, Takenaka T, Váncza J, Monostori L (2009) Value Creation and Decision-making in Sustainable Society. Annals of the CIRP 58(2):681-700.

[274] Ulrici A, Serranti S, Ferrari C, Cesare D, Foca G, Bonifazi G (2013) Efficient Chemometric Strategies for PET-PLA Discrimination in Recycling Plants Using Hyperspectral Imaging. Chemometrics and Intelligent Laboratory Systems 122:31-39.

[275] Umeda Y, Kondoh S, Sugino T (2006) Analysis of Reusability using 'Marginal Reuse Rate'. Annals of the CIRP 55(1):41-44.

[276] Umeda Y, Fukushige S, Tonoike K (2009) Evaluation of Scenario-based Modularization for Lifecycle Design. Annals of the CIRP 58(1):1-4.

[277] Umeda Y, Takata S, Kimura F, Tomiyama T, Sutherland J-W, Kara S, Herrmann C, Duflou J-R (2012) Toward Integrated Product and Process Life Cycle Planning-An Environmental Perspective. Annals of the CIRP 61(2):681-702.

[278] Umeda Y, Fukushige S, Mizuno T, Matsuyama Y (2013) Generating Design Alternatives for Increasing Recyclability of Products. Annals of the CIRP 62(1): $135-138$.

[279] Umeda Y, Miyaji N, Shiraishi Y, Fukushige S (2015) Proposal of a Design Method for Semi-destructive Disassembly with Split Lines. Annals of the CIRP 64(1):29-33.

[280] Urano K, Takata S (2013) Module Reconfiguration Management for Circular Factories without Discriminating Between Virgin and Reused Products: Reengineering Manufacturing for Sustainability. Procedia CIRP 603-608.

[281] UNEP-United Nations Environment Program (2013) International Resource Panel, Metal Recycling: Opportunities, Limits, Infrastructure.

[282] Van den Bossche W, Peeters J-R, Devolder T, Duflou J-R, Dewulf W (2014) Proof of Concept of an Elastomer Based Fastener Enabling Rapid Disassembly. Procedia CIRP 15:234-238.

[283] Van Schaik A, Reuter M-A (2010) Dynamic Modeling of E-waste Recycling System Performance Based on Product Design. Minerals Engineering 23(3): 192-210.

[284] Vanegas P, Peeters J-R, Dewulf W, Cattrysse D, Duflou J-R (2015) Improving Resource Efficiency through Recycling Modelling: A Case Study for LCD TVs. 12th Glob Conf Sustain Manuf-Emerg Potentials 26:601-606.

[285] Vonbungyong S, Kara S, Pagnucco M (2012) Basic Behaviour Control of the Vision-based Cognitive Robotic Disassembly Automation. Journal of Assembly Automation 33(1):38-56.
[286] Vongbunyong S, Kara S, Pagnucco M (2013) Application of Cognitive Robotics in Disassembly of Products. Annals of the CIRP 62(1):31-34.

[287] Vongbunyong S, Kara S, Pagnucco M (2013) Basic Behaviour Control of the Vision-based Cognitive Robotic Disassembly Automation. Assembly Automation 33:38-56.

[288] Vongbunyong S, Chen W-H (2015) Disassembly Automation: Automated Systems with Cognitive Abilities, Springer Edition.

[289] Van Wassenhove L-N, Zikopoulos C (2010) On the Effect of Ouality Overestimation in Remanufacturing. International Journal of Production Research 48:5263-5280.

[290] Wang L, Wang X-V, Gao L, Vancza J (2014) A Cloud-based Approach for WEEE Remanufacturing. Annals of the CIRP 63(1):409-413.

[291] Wang Y, Liu J-H (2010) Chaotic Particle Swarm Optimization for Assembly Sequence Planning. Robotics and Computer-Integrated Manufacturing 26 (2):212-222.

[292] Watson M (2008) A Review of Literature and Research on Public Attitudes, Perceptions and Behaviour Relating to Remanufactured, Repaired and Reused Products - Report of the Centre for Remanufacturing and Reuse.

[293] Wei S, Tang O, Sundin E (2015) Core (product) Acquisition Management for Remanufacturing: A Review. Journal of Remanufacturing 5(4).

[294] Weyrich M, Wang Y (2013) Architecture Design of a Vision-based Intelligent System for Automated Disassembly of E-waste with a Case Study of Traction Batteries. 2013 IEEE 18th Conference on Emerging Technologies \& Factory Automation.

[295] Westkämper E (2003) Assembly and Disassembly Processes in Product Life Cycle Perspectives. Annals of the CIRP 52(2):579-588.

[296] Westkämper E, Feldmann K, Reinhart G, Seliger G (1999) Integrated Development of Assembly and Disassembly. Annals of the CIRP 48(2):557565.

[297] Widera H, Seliger G (2015) Methodology for Exploiting Potentials of Remanufacturing by Reducing Complexity for Original Equipment Manufacturers. Annals of the CIRP 64(1):463-466.

[298] Wiendahl H-P, ElMaraghy H, Nyhuis P, Zah MF, Wiendahl H-H, Duffie N, Brieke M (2007) Changeable Manufacturing - Classification, Design and Operation. Annals of the CIRP 56(2):783-809.

[299] Wiendahl H, Scholz-Reiter B, Burkner S, Scharke H (2001) Flexible Disassembly Systems Layouts and Modules for Processing Obsolete Products. IMechE 723-732.

[300] Willems B, Dewulf W, Duflou J-R (2007) Active Snap-fit Development Using Topology Optimization. International Journal of Production Research 45:41634187.

[301] Willems B, Dewulf W, Duflou J-R (2007) Pressure-triggered Active Fasteners: Design Results Using Topology Optimization. Proceedings of the 2007 IEEE International Symposium on Electronics \& the Environment 184-189.

[302] Williams JA-S (2006) A Review of Electronics Demanufacturing Processes. Resources Conservation and Recycling 47:195-208.

[303] Wolf M-I, Colledani M, Gershwin S-B, Gutowski T-G (2013) A Network Flow Model for the Performance Evaluation and Design of Material Separation Systems For Recycling. IEEE Transactions on Automation Science and Engineering 10:65-75.

[304] World Economic Forum (2014) Towards the Circular Economy: Accelerating the Scale-up Across Global Supply Chains.

[305] Wu H-Q, Shi Y, Xia Q, Zhu W-D (2014) Effectiveness of the Policy of Circular Economy in China: A DEA-based Analysis for the Period of 11 th five-year plan. Resources Conservation and Recycling 83:163-175.

[306] Xu Z, Pokharel S, Elomri A, Mutlu F (2017) Emission Policies and Their Analysis for the Design of Hybrid and Dedicated Closed-loop Supply Chains. Journal of Cleaner Production 142(4):4152-4168.

[307] Yeh W-C (2012) Simplified Swarm Optimization in Disassembly Sequencing Problems with Learning Effects. Computers \& Operations Research 39(9): 2168-2177.

[308] Yi P, Huang M, Guo L, Shi T (2016) A Retailer Oriented Closed-loop Supply Chain Network Design for End of Life Construction Machinery Remanufacturing. Journal of Cleaner Production 124:191-203.

[309] Yin R, Cao H, Li H, Sutherland J-W (2014) A Process Planning Method for Reduced Carbon Emissions. International Journal of Computer Integrated Manufacturing 27(12):1175-1186.

[310] Yuksel H (2010) Design of Automobile Engines for Remanufacture with Quality Function Deployment. International Journal Of Sustainable Engineering 3(3):170-180.

[311] Zikopoulos C, Tagaras G (2008) On the Attractiveness of Sorting before Disassembly in Remanufacturing. IIE Transactions 40:313-323. 